\title{
EL PROCESO DE ABSORCIÓN DEL REAL TRIBUNAL DEL PROTOALBEITARATO POR LA ESCUELA DE VETERINARIA DE MADRID (1792-1855)
}

\section{Ángel Salvador Velasco, M. ${ }^{a}$ Luisa de Andrés Turrión y Joaquín Sánchez de Lollano Prieto"}

Universidad Complutense de Madrid

\begin{abstract}
RESUMEN
La absorción del Real Tribunal del Protoalbeitarato ${ }^{1}$ por la Escuela de Veterinaria de Madrid presenta ciertas singularidades respecto al proceso equivalente en medicina y farmacia. La pugna y hegemonía del Real Tribunal durante casi sesenta años desde la creación de la Escuela de Veterinaria (1792), ha sido estudiada por la historiografía tradicional con una visión centrada fundamentalmente en aspectos veterinarios. En el presente artículo se investigan en detalle los procesos conducentes a la absorción y se pone de manifiesto la relevancia de las motivaciones políticas y su predominio sobre las de carácter técnico, sanitario o profesional. Por ello, se analiza el juego de instituciones y de agentes externos a la veterinaria implicados, en especial destacamos el papel desempeñado por el XV Marqués de Cerralbo.
\end{abstract}

PALABRAS CLAVE: Albeitería. Real Tribunal del Protoalbeitarato. Veterinaria. Real Caballeriza. Marqués de Cerralbo. España. Siglo XVIII. Siglo XIX.

THE TAKEOVER PROCESS OF THE REAL TRIBUNAL DEL PROTOALBEITARATO BY THE FACULTY OF VETERINARY OF MADRID (1792-1855)

* Joaquín Sánchez de Lollano Prieto, Historia de la Veterinaria, Pabellón de Anatomía, $2^{\mathrm{a}}$ planta, Facultad de Veterinaria, UCM, Av. Puerta de Hierro, s/n, Madrid, 28040, Tel.: 91 39437 89, jsdelollano@vet.ucm.es.

1 A lo largo del presente artículo se empleará la denominación motivada de Protoallbeitarato. Sus equivalentes de profesiones sanitarias, Protomedicato, Protocirujanato y Protofarmaceuticato, toman su denominación del profesional que ejerce la facultad, por lo que en el caso del albéitar corresponde añadir el sufijo -ato; véase: SAlVADOR VElASCO, A. y ANDRÉS TURRIÓN, M. ${ }^{a}$ L. DE (2005), El Marqués de Cerralbo, Caballerizo Mayor de la Reina Gobernadora, impulsor de la absorción del Tribunal del Protoalbeitarato por la Escuela de Veterinaria. En RAMírEZ ZARZOSA, G., GIL CANO, F. y VÁzQuez Autón, J.M. a (eds.), XI Congreso Nacional de Historia de la Veterinaria, Asociación Murciana de Historia de la Veterinaria, Murcia, p. 154. 


\begin{abstract}
The absorption of the Real Tribunal del Protoalbeitarato by the Veterinary Science School of Madrid shows several singularities in relation to the equivalent process in medicine and pharmacy. The conflict and the hegemony of the Real Tribunal during almost sixty years from the creation of the Veterinary Science School (1792), has been studied by the traditional historiography with a view fundamentally focused on veterinary aspects. In this article, the process of absorption is investigated in full detail. Also, the relevance of political motivations and their predominance over technical, sanitary or professional motivations are shown. So, the game of institutions and agents which are external to the veterinary science are analysed; specially, the outstanding role performed by the XV Marquis of Cerralbo.
\end{abstract}

KEY WORDS: Albeitería. Real Tribunal del Protoalbeitarato. Veterinary. Royal Stable. Marquis of Cerralbo. Spain, $18^{\text {th }}$ Century. $19^{\text {th }}$ Century.

\title{
INTRODUCCIÓN
}

La renovación y sustitución de la secular albeitería española por la veterinaria es, en su inicio, producto de la Ilustración. Entre los factores desencadenantes del proceso se han considerado la creación de Escuelas de Veterinaria en Europa, los avances producidos en ciencias, y la necesidad de un profesional más eficaz y mejor formado para la asistencia de los équidos del ejército y el aumento de la riqueza pecuaria ${ }^{2}$. En el resto de las monarquías europeas, la veterinaria emerge sin otra competencia que la de caballerizos y herradores ${ }^{3}$. Sin embargo, en España se encuentra con la albeitería, un modo consolidado de ejercer y entender la práctica clínica veterinaria y unas instituciones que lo respaldan y articulan. Esto, en lugar de ser una ventaja, produjo graves inconvenientes al entrar en conflicto la recién creada Escuela de Veterinaria con las veteranas instituciones de la albeitería: el Real Tribunal del Protoalbeitarato y la Real Caballeriza, de la que surgen los Alcaldes Examinadores de aquél.

En medicina, cirugía y farmacia, los nuevos centros docentes, producto de las reformas de finales del siglo XVIII, lograron la absorción de los cometi-

2 ViVes VAllÉs, M.A. (2000), La Real Escuela de Veterinaria de Madrid. ¿Una de las medidas del Gobierno para mejorar la albeitería?, Conferencia pronunciada en la Real Academia de Ciencias Veterinarias en la sesión de 10 de febrero de 1999, Anales de la Real Academia de Ciencias Veterinarias, Madrid, 6, pp. 127-140; Benito HernándeZ, M. (2003), Del amanecer de las escuelas de Veterinaria en España, Moncada (Valencia), Universidad Cardenal Herrera-CEU, pp. 91-95.

3 Dunlop, R.H. y Williams, D.J. (1996), Veterinary Medicine: An Illustrated History, St. Louis, Mosby, pp. 291, 321; LeClainche, E. (1955), Histoire illustrée de la médecine vétérinaire, Mónaco, Albin Michel, vol. I, p. 216, vol. II, pp. 83-86. 
dos profesionales previos y de las instituciones que los regulaban (Tribunal del Protomedicato). El proceso, a diferencia de veterinaria, se realizó en un periodo anterior (1822) y de modo más rápido, aunque no estuvo exento de complicaciones, con ceses y restablecimientos del citado Tribunal ${ }^{4}$.

En veterinaria, desde la apertura en 1793 de la Real Escuela de Madrid, hasta la absorción del Real Tribunal del Protoalbeitarato en 1835 y su cese efectivo en 1847 (con exámenes de gracia hasta 1852-1855), sucede un largo y complejo periodo ${ }^{5}$. La supresión de la albeitería a favor de la veterinaria se verá condicionada por una serie de factores que se analizan en el artículo. La nueva profesión, con mayores posibilidades de desarrollo, entró en competencia con la albeitería, estancada en planteamientos y práctica $^{6}$, aunque tenía a su favor la economía de tiempo, de recursos y su amplia implantación en toda la nación. Esta pugna tenía como fondo la oposición entre dos criterios e ideologías presentes en muchos conflictos de la Ilustración española. Lo que se dirime, mas allá de la formación de los nuevos profesionales encargados de la sanidad animal, es una lucha entre instituciones, entre el criterio conservador propio del Antiguo Régimen, partidario del modelo profesional gremial con formación por pasantía y evaluación delegada en tribunales más o menos dependientes, y el modelo liberal, sostenido por ilustrados y renovadores, que abogan por un ejercicio libre con formación organizada y regulada, de indudable mayor coste económico y social, y llevada a cabo en centros docentes con mayor control y capacidad evaluadora.

4 Véase: IBORRA, P. (1987), Historia del Protomedicato en España (1477-1822), edición, introducción e índices RIERA J. y GRANDA-JUESAS J., Valladolid, Universidad de Valladolid; LóPez Terrada, M.'․․ y Martínez Vidal, A. (eds.) (1996), El Tribunal del Protomedicato en la Monarquía Hispánica, Dynamis, 16; CAMPos DíEz, M. ${ }^{a}$ S. (1999), El Real Tribunal del Protomedicato castellano (siglos XIV-XIX), Cuenca, Universidad de Castilla La Mancha.

5 El Real Tribunal del Protoalbeitarato gozaba de plena organización desde el siglo XV, como institución encargada de otorgar, previo examen, el título de Maestro Herrador y Albéitar que permite el ejercicio público de la profesión en toda España. Los últimos exámenes de gracia y dispensas alcanzaron, según Sanz Egaña, hasta el año 1855; véase: SANZ EGAÑA, C. (1941), Historia de la Veterinaria Española, Madrid, Espasa-Calpe, pp. 86-90. Para contrastar las diferentes razones de la absorción en medicina, farmacia y veterinaria, véase: BENITO HERNANDEZ (2003), pp. 53-57.

6 Como señala Dualde, el Real Tribunal a su vez arrastraba un cierto desgaste por los contenciosos con los tribunales gremiales, su evidente desfase en la formación y posteriormente la propia descomposición, con frecuentes irregularidades en sus representantes periféricos o centrales; véase: DuAlde PéRez, V. (1997), Historia de la Albeytería Valenciana, Valencia, Ayuntamiento de Valencia, pp.148, 193, 195. 
Desde la historiografía veterinaria, la larga pugna con la albeitería y la excesiva permanencia del Tribunal han sido valoradas de una manera muy negativa por algunos autores, haciéndolas responsables del retraso de la naciente Ciencia Veterinaria ${ }^{7}$. Otros autores sólo han considerado el retraso en el aspecto de la formación y han justificado la permanencia del Real Tribunal al permitir éste paliar el reducido número de veterinarios que salían de la Escuela, insuficiente para atender las necesidades del país, y favorecer por otro lado la posterior penetración de los veterinarios gracias a la difusión de la albeitería $^{8}$. Con independencia de la valoración que otorguen, es común en todos ellos el análisis centrado en aspectos veterinarios, con protagonistas, motivaciones y consecuencias veterinarias, en definitiva, un proceso visto desde la veterinaria y para la veterinaria. Asimismo, coinciden en destacar entre las causas de la absorción las de tipo socio-económico y profesional, concediendo un excesivo peso a los protagonistas veterinarios.

Por lo anterior, un proceso de la relevancia histórica en el inicio de la veterinaria española como es la fusión del Real Tribunal del Protoalbeitarato y de la Escuela de Veterinaria de Madrid, requiere un análisis más amplio, que incluya otras instituciones implicadas y que profundice en los procesos colaterales concatenados en la absorción, hasta ahora no estudiados. Abordamos por ello el juego de instituciones y personas en el complicado proceso que permitió que la veterinaria avanzara y destacamos el papel desarrollado por un notable liberal, el XV Marqués de Cerralbo.

\section{Vinculación entre Real Caballeriza, Real Tribunal del Protoal- BEITARATO Y REAL ESCUELA DE VETERINARIA}

Los análisis efectuados por los historiadores de la veterinaria se han centrado en los dos contendientes, Tribunal y Escuela, omitiendo a un tercer actor, la Real Caballeriza, cuya importancia abordamos en este artículo. Procede por ello, analizar primero la peculiar relación entre las instituciones implicadas.

7 Este análisis más peyorativo es característico de los primeros autores veterinarios, como Casas de Mendoza, Llorente Lázaro y Morcillo y Olalla.

8 SAnZ Egaña (1941), p. 90; SuÁrez, G. (ed.) (1994), Libro conmemorativo del Bicentenario de la Facultad de veterinaria, 1793-1993, Madrid, UCM, p. 63; VITAL RUIBÉRRIZ DE TORRES, P. (1984), Historia de la Ciencia Veterinaria Española: del Antiguo Régimen al Liberalismo 1792-1847, tesis doctoral dirigida por PESET REIG, J.L., Madrid, UCM, p. 39; BENITO HERNÁNDEZ (2003), p. 67. 
El nombramiento como Herrador y Albéitar de Número de la Real Caballeriza suponía alcanzar la máxima cualificación dentro de la profesión, llevaba anexo sin excepción, el título de Alcalde Examinador del Real Tribunal del Protoalbeitarato9. La vinculación, de antigüedad secular, entre Real Caballeriza y Real Tribunal del Protoalbeitarato es absoluta ${ }^{10}$. Un Ayuda de Herrador de la Real Caballeriza, el Maestro albéitar Bernardo Rodríguez, pensionado en 1776 en la Escuela de Veterinaria de Alfort (Francia), será el primer veterinario español e inicialmente el escogido para impulsar la veterinaria y renovar la albeitería. Sin embargo, son los también pensionados para su formación veterinaria en Alfort (1784), Segismundo Malats i Codina e Hipólito Estévez y Va1lejo, Mariscales Mayores de Regimientos de Dragones, los que finalmente desempeñarán este cometido. De ambos, como describimos a continuación, el primero destaca por liderazgo e importancia en el proceso de la absorción.

En mayo de 1790 se produce el nombramiento de Malats como Herrador y Albéitar supernumerario de la Real Caballeriza ${ }^{11}$, dos años después, en marzo de 1792, se le nombra por Real Orden Director Primero de la futura Escuela de Veterinaria, cuya apertura tiene lugar en octubre de 1793. Ese mismo año

9 Los albéitares de la Real Caballeriza estaban dedicados al herrado y la asistencia clínica de la numerosa caballeriza de la Real Casa. Una vez producido el nombramiento como Mariscal de Número de la Real Caballeriza y la posterior toma de juramento en manos del Caballerizo Mayor, la Real Cámara de Castilla expedía el título de Alcalde Examinador, previo Real Decreto dirigido a ella por Mayordomía Mayor con el nombramiento realizado por el Rey, realizándose el juramento de la plaza en la Sala de Alcaldes de Casa y Corte del Consejo de Castilla. Así lo constatamos después de haber estudiado numerosos nombramientos en la Real Caballeriza (Archivo General de Palacio, en adelante AGP) y tomas de juramento como Alcalde Examinador (Archivo Histórico Nacional, en adelante AHN)

10 Sin perjuicio de datos a investigar en anteriores periodos, desde 1475 los Herradores y Albéitares de Número de la Real Caballeriza son los únicos Alcaldes Examinadores del Real Tribunal del Protoalbeitarato. Según documentación del Archivo General de Simancas, Registro General del Sello, a 24-05-1475 la Reina Isabel I nombra ferrador e alcalde examinador mayor a Francisco de Peñalosa; véase: SANZ EgAÑA, C. (1952), Nombramientos de albéitares, alcaldes y examinadores hechos por los Reyes Católicos (1475-1489), Revista de Ciencia Veterinaria, 96, pp. 361-390; y posteriormente, HERRERO ROJO, M. (1990), La Veterinaria en la antigüedad: Creación del Real Tribunal del Protoalbeiterato de Castilla, Valladolid, Junta de Castilla y León, Consejería de Cultura, pp. 104-119.

11 El 12-05-1790 Malats jura el cargo en manos del Caballerizo Mayor, Marqués de Villena; Salvador Velasco, A., Pérez García, J.M. y Sánchez De lollano Prieto, J. (2006a), Aportación a los nombramientos de Segismundo Malats (c.1747-1826) en la Real Caballeriza. En Rojo, F., MARTíneZ, J.M. y FERnÁNDEZ, J.G. (coords.), XXXVII International Congress of the World Association for the History of Veterinary Medicine, León, Mic, pp. 247-252. 
es nombrado Alcalde Examinador del Protoalbeitarato ${ }^{12}$. En la persona de Segismundo Malats confluyen las tres instituciones y se produce así una peculiar situación que podría haberse decantado en una firme apuesta por la veterinaria al haberle sido confiado el cargo de Director de la Escuela ${ }^{13}$. Su actitud se llega a calificar desde la óptica veterinaria como «traición al legislador» ${ }^{14}$. Sin embargo ¿era realmente la motivación del legislador del momento la sustitución de la albeitería por la veterinaria? Un análisis que siga un discurso explicativo de tintes menos internalistas evidencia que la única escuela, ubicada en Madrid, no podía abastecer al país de suficientes profesionales. Por otro lado, en un periodo histórico de sucesivas crisis resultaba mucho más económica la formación por pasantía y el examen por tribunales independientes ${ }^{15}$. La lucha de intereses marcará el futuro de la naciente Escuela de Veterinaria y, por ende, de la nueva profesión.

\section{INTENTOS DE ABSORCIÓN DEL REAL TRIBUNAL DEL PROTOALBEITARATO POR LA ESCUELA DE VETERINARIA}

Entre los numerosos intentos de absorción producidos dedicaremos una especial atención a dos de ellos. El primero, coincidente con la apertura de la Escuela, por su importancia y las secuelas que deja, y el último, en 1835, que será objeto de análisis detallado en nuestro artículo.

12 Un día después del fallecimiento del Herrador y Albéitar de Número de la Real Caballeriza Francisco Morago, producido el 7 de agosto de 1793, se nombra por Orden del Caballerizo Mayor a Segismundo Malats para ocupar dicha plaza, prestando juramento a $10 \mathrm{de}$ agosto. Este documento tiene el valor adicional de ser el primer juramento en el que la denominación oficial de la plaza varía de Herrador y Albéitar de Número de la Real Caballeriza a Mariscal de Número de la Real Caballeriza; véase: SAlvador, PÉreZ y SÁnCHEz De LollaNO (2006a). El título firmado por el Rey a 9 de septiembre de 1793 es presentado por Segismundo Malats ante la Sala primera de Alcaldes de Casa y Corte del Consejo de Castilla junto con la solicitud de toma de juramento, que tuvo lugar ante los diez componentes de la Sala el 16 de septiembre; AHN, Consejo de Castilla, Sala de Alcaldes de Casa y Corte, libro de gobierno 1384, folios 482-487.

13 SanZ EgaÑa (1941), pp. 80-81. Resume el discurso de los historiadores veterinarios anteriores (Casas, Llorente y Morcillo y Olalla), emitiendo una rotunda valoración negativa de la actuación de Malats por su defensa del Tribunal del Protoalbeitarato, cimentada según estos autores en las prebendas y ventajas económicas que le reportaba.

14 SANZ EGAÑa (1941), p. 284.

15 SUÁREZ (1994), pp. 63-64. 
Respecto del primero, aportamos nuevos datos y corroboramos con ellos el criterio mantenido por Vital Ruibérriz de Torres ${ }^{16}$, quien considera que los intentos de absorber el Tribunal son simultáneos a la creación de la Escuela, mostrándose contrario a la primera de las fases del proceso establecidas por Sanz Egaña ${ }^{17}$.

La documentación consultada resulta esclarecedora. Segismundo Malats, doce días después de abrir sus puertas la Escuela de Veterinaria de Madrid, de la que es Director Primero y profesor, y cuarenta y cinco días después de ser nombrado Alcalde Examinador del Real Tribunal del Protoalbeitarato, aboga por la desaparición del Tribunal ideando una fórmula no traumática de absorción por la Escuela. El 30 de octubre de 1793 realiza junto a Hipólito Estévez, Director Segundo de la Escuela y profesor, una solicitud ante Mayordomía Mayor en la que exponen la conveniencia de que a partir de ese momento, los dos Directores de la Escuela de Veterinaria junto con los tres Alcaldes Examinadores del Tribunal del Protoalbeitarato, sean los encargados de realizar conjuntamente los exámenes, tanto a los alumnos de la Escuela como a los aspirantes al título de Maestro herrador y albéitar. Proponen asimismo ir reduciendo de forma paulatina el número de examinadores a medida que se produzca el fallecimiento de los miembros del Tribunal, cuyo nombramiento es vitalicio, hasta quedar formada la Junta Examinadora únicamente por los dos Directores de la Escuela y por un Alcalde Examinador. De esta forma, la Escuela pasaría a tener el control del Tribunal. Por último, proponen que se aplique la jurisdicción del Tribunal del Protoalbeitarato conforme a la Planta en vigor del Tribunal del Protomedicato, y que «a beneficio de la humanidad y de la escuela» no sean nombrados nuevos Protoalbéitares en Aragón, Cataluña y Valencia ${ }^{18}$.

16 Vital Ruiberriz De TORRes (1984), pp. 73-82.

17 En los intentos de absorción del Tribunal por parte de la Escuela de Veterinaria, Sanz Egaña aprecia «tres fases perfectamente definidas»: $1 .^{\text {a }}$, reorganización del Protoalbeitarato en $1794 ; 2{ }^{\mathrm{a}}$, intentos de fusión entre ambas instituciones en 1818,1822 y definitivamente en 1835; 3. a , supresión definitiva del Protoalbeitarato por Real Decreto de 19 de agosto de 1847 , con prórroga hasta 1850; véase: SANZ EGAÑA (1941), p. 80.

18 Archivo General de la Administración (en adelante AGA), c. ${ }^{a}$ 32/16360. Los Directores de la Escuela de Veterinaria solicitan la Real aprobacion de la Junta que proponen para el examen de los Profesores de esta ciencia, San Lorenzo a 4-11-1793. La solicitud, apoyada por el Protector de la Escuela y Consejero de la Cámara de Castilla Domingo Codina, fue aprobada a 29-12-1793, solicitando informe al Consejo de la Cámara de Castilla y al Ministerio de Gracia y Justicia. Nuevamente, a 29-08-1794 los Directores de la Escuela repiten la solicitud en los mismos términos, sin obtener tampoco respuesta alguna. 
Segismundo Malats cambiará su criterio, pasando a ser defensor a ultranza no sólo del mantenimiento del Real Tribunal, sino de su preponderancia sobre la Escuela. Queda establecida así por mucho tiempo una situación difícil de resolver, coexisten dos profesiones, una maestría y una profesión liberal, con muy distinta formación pero con un mismo destino, la asistencia clínica y el herrado del caballo.

Desde ese primer intento se suceden otros de importancia e intensidad variables. En 1795 se determina por Real Decreto que el Tribunal del Protoalbeitarato esté formado por cinco Alcaldes Examinadores, los tres Mariscales de Número de la Real Caballeriza y los dos Directores de la Escuela de Veterinaria. Estos mismos términos están incluidos en el Artículo 5. ${ }^{\circ}$ de la Ordenanza de la Escuela aprobada en el año 1800. No afecta a Malats por ser ya Mariscal de Número de la Real Caballeriza, pero sí a Hipólito Estévez, que sin embargo no juró su nombramiento como Alcalde Examinador hasta 29 julio de $1802^{19}$, desempeñándolo hasta su fallecimiento en abril de 1812 . De esta manera se vinculan ambas instituciones, pero el control del Protoalbeitarato lo sigue ostentando la Real Caballeriza ${ }^{20}$.

Tras la Constitución de 1812 se produjo la supresión de gremios y tribunales y esto afectó también al Protoalbeitarato. Acogiéndose al Decreto de 8 de junio de 1813 la Escuela no sólo no se vio favorecida sino que el intrusismo tuvo las puertas abiertas. Por otro lado, el Real Tribunal sería repuesto al poco tiempo por Fernando VII ${ }^{21}$. En 1818 se produjo otro intento, en el que se mostró el gran interés del Protector y del profesorado, salvo Malats, quien

19 AHN, Consejo de Castilla, Sala de Alcaldes de Casa y Corte, libro de gobierno n. ${ }^{\text {o }}$ 1392, folios 1293-1299.

20 AGP, Reinado Fernando VII, Personal, c. ${ }^{\text {a }}$ 271/11. No volvió a producirse nombramiento alguno por este concepto hasta que por Real Orden comunicada por Mayordomía Mayor al Caballerizo Mayor a 29-02-1820, se adjunta oficio del Secretario de Estado del Despacho de Gracia y Justicia mandando expedir el título de Alcalde Examinador del Tribunal del Protoalbeitarato a favor del Catedrático y reconocido liberal Antonio Bobadilla, en su calidad de Director Segundo de la Escuela de Veterinaria. Será la última ocasión en la que esta prerrogativa se cumpla. AGP, Reinado Fernando VII, Caballerizas, c. ${ }^{\text {a } 414 / 7}$. Por Real Orden de 4-06-1828 se denegó la solicitud de nombramiento como Alcaldes Examinadores a los Directores Primero y Segundo realizada por el Duque de Alagón, Protector de la Escuela. Y de forma definitiva, la Real Orden de 4-07-1830 ordena que el Tribunal del Protoalbeitarato esté formado únicamente por los tres individuos que ocupen plaza de Mariscal de Número de la Real Caballeriza.

21 Vital Ruiberriz De Torres (1984), p. 75; Fernandez IsASMEndi, E. (1893), Antigüedad de la Veterinaria e historia del periodismo de esta ciencia, Madrid, Bailly-Bailliere e hijos, pp. 45-47. 
logró finalmente entorpecer el proceso ${ }^{22}$. Conscientes de la incapacidad de la única escuela para abastecer de profesionales veterinarios, lo que pretendían era absorber el Tribunal para elevar la formación del albéitar. Hay que destacar que la Junta de profesores argumenta el ejemplo del Protomedicato, Protocirujanato y Protofarmaceuticato. Para dar mayor rigor a los exámenes proponen, como en medicina y farmacia, que sean los profesores de la Escuela los que realicen los exámenes y que sean, como en aquellas, dos ejercicios, uno teórico y otro práctico y no sólo el teórico ${ }^{23}$.

Durante el Trienio Liberal se produjo la absorción momentánea del Protoalbeitarato por la Escuela, al pasar a depender esta última de la Dirección de Estu$\operatorname{dios}^{24}$. Contra esta medida, Segismundo Malats eleva una instancia al Rey el 22 de mayo de 1822 y en ella muestra su desacuerdo con el contenido de la Real Orden, califica la reunión de las dos instituciones como «carente de todo fundamento», y defiende enérgicamente sus privilegios como Alcalde Examinador, siendo apoyado en su informe por el Caballerizo Mayor, Marqués de Bélgida ${ }^{25}$. No lograron variar la resolución tomada, lo que lleva a Malats a solicitar la jubilación como Director Primero de la Escuela alegando motivos de salud ${ }^{26}$.

La restauración del absolutismo por Fernando VII permite a Malats volver a hacerse con el control de la Escuela de Veterinaria y ejercer como Alcalde Examinador del Tribunal del Protoalbeitarato. Y lo que es más importante para el futuro del Tribunal, el Caballerizo Mayor durante el periodo liberal, el Conde de Altamira, es destituido el 1 de octubre de 1823 y confirmado en la plaza en esa misma fecha el Marqués de Bélgida ${ }^{27}$. Éste se erigirá en defensor del Real Tribunal del Protoalbeitarato como institución del Antiguo Régimen.

22 SANZ EgAÑa (1941), pp. 81-82. Referente a este intento, Sanz Egaña afirma «nada extraño que la idea de la fusión surgiera espontáneamente y circulase con insistencia entre los profesionales, mucho mas después de haber sido reformados los tribunales del Protomedicato y del Protoboticariato, refundidos en las respectivas Escuelas de medicina y de farmacia».

23 Vital Ruiberriz De TORRES (1984), p. 73.

24 SANZ EgAÑA (1941), p. 82. Sanz Egaña detalla las Reales Órdenes que dan lugar a esta fusión, suspendiendo los Alcaldes Examinadores del Protoalbeitarato sus actividades.

25 Salvador Velasco, A. (2004), Medicamento de uso animal: nexo de dos Reales instituciones, Real Caballeriza y Real Botica (1789-1868), tesis doctoral dirigida por ANDRÉS TURRIÓN, M. ${ }^{a} L$. DE, Madrid, UCM, pp. 50-52. Por su interés y novedad se reproduce la instancia en su totalidad en la citada tesis.

26 Vital RuibÉRriz De TORRes (1984), p. 77. Malats continúa percibiendo el cobro de los 30.000 reales que tiene asignados. Fue finalmente separado de su destino a 28 de marzo de 1823 por la Dirección de Estudios del Gobierno Revolucionario.

27 AGP, Expediente personal del Marqués de Bélgida, c. ${ }^{a} 16605 / 4$. Previamente a su confirmación, había comenzado su tercer periodo como Caballerizo Mayor en agosto de 1823, 
Como caso ilustrativo de dicha defensa, citamos los intentos de preeminencia de la Escuela de Veterinaria sobre el Real Tribunal planteados por los Protectores Pedro de Sotomayor en $1824^{28}$ y el Duque de Alagón en $1827^{29}$. Ambos se verán frenados por la frontal oposición del Caballerizo Mayor, que apoya los antiguos derechos de los Mariscales de Número de la Real Caballeriza y Alcaldes Examinadores del Tribunal del Protoalbeitarato en sus informes ante Mayordomía Mayor, que es finalmente quien toma las decisiones.

\section{Motivos de la Subsistencia del Real Tribunal del Protoalbeitarato}

La albeitería, destinada a desaparecer con el nacimiento de la veterinaria, perduró durante casi sesenta años más. En la dualidad albeitería-veterinaria se ha concedido una importancia capital al papel desempeñado por ciertos profesores (Risueño y Bobadilla ${ }^{30}$ ), la totalidad de la junta docente ${ }^{31}$ o el Protector de la Escuela (Félix Colón ${ }^{32}$, Pedro de Sotomayor ${ }^{33}$ y especialmente al Duque de Alagón, quien demostrará una gran perseverancia en la defensa de los derechos de la Escuela y de sus Catedráticos ${ }^{34}$ ). Sin embargo, ninguno de ellos verá cumplido su objetivo hasta que no se produzcan cambios en los mediadores políticos.

Por otro lado, este análisis tradicional destaca entre los motivos que dificultan el fin de la albeitería, su trayectoria secular, la capacidad de influencia de los Mariscales de Número de la Real Caballeriza en la defensa de sus inte-

tras ser nombrado por Regencia del Reino. Ejerció como Caballerizo Mayor de 28-03-1798 a 9-12-1803; de 27-03-1814 a 4-08-1822; y de 2-08-1823 a 12-10-1833.

28 PÉREz GARCíA, J.M. (2001), D. Pedro Sotomayor, protector de la antigua escuela de Veterinaria de Madrid, sus gestiones para reunir a dicho Centro Docente el Tribunal del protoalbeitarato, Conferencia pronunciada en la Real Academia de Ciencias Veterinarias en la sesión de 8 de noviembre de 2000, Anales de la Real Academia de Ciencias Veterinarias, 9, pp. 39-51.

29 El Duque de Alagón es nombrado Protector de la Escuela de Veterinaria en marzo de 1825, en 1827 promueve un intento de absorción; véase: SANZ EGAÑA (1941), p. 82; VITAL RUIBÉRRIZ DE TORRES (1984), p. 81.

30 SAnZ Egaña (1941), pp. 258, 259, 262; Vital RuibÉrriz De Torres (1984), p. 81.

31 Llorente Lázaro, R. (1856), Compendio de la Bibliografia de la Veterinaria Española, con algunas noticias históricas de esta Ciencia en nuestra patria, y con las reglas de moral á que debe el veterinario ajustar su conducta facultativa, Madrid y Santiago, Imp. Angel Calleja, p. 15; DuALDE (1997), p. 205.

32 SANZ EgaÑa (1941), pp. 253-255.

33 PÉREZ GARCÍA (2001).

34 FERNÁNDEZ ISASMENDI (1893), p. 43; SANZ EgAÑA (1941), p. 260. 
reses económicos o el escaso interés de ciertos Protectores de la Escuela ${ }^{35}$. Concede por ello gran importancia a la motivación social y fundamentalmente a la económica. Sin embargo, en el desarrollo del análisis todo aparece mezclado, englobando el prestigio secular, la aceptación social y las razones económicas con el factor personal, a través de las intrigas e intereses de Segismundo Malats y el resto de Mariscales de Número $^{36}$.

Probablemente, las razones económicas, dentro de las apuntadas, sean de las de mayor peso y explican en buena medida la defensa del Protoalbeitarato por sus titulares y por qué la veterinaria tuvo que convivir después con el Tribunal ${ }^{37}$. Hay aquí un hecho diferencial con el Protomedicato: en éste los derechos de examen revierten al arca del Tribunal, teniendo asignado cada Protomédico un sueldo fijo ${ }^{38}$. En el Protoalbeitarato los titulares del Tribunal perciben la mayor parte de los ingresos. Este lucro personal de los Protoalbéitares se contrapone, como veremos, con la penuria económica de la Escuela.

Respecto a este último factor, aportamos datos complementarios. El Reglamento de la Escuela de Veterinaria aprobado por Real Orden a 12 de febrero de 1793, establecía que su financiación se realizará con la consignación del uno por ciento de «Propios y Arbitrios del Reino» ${ }^{39}$. Según Llorente Láza-

35 DuAlde (1997), pp. 221-222.

36 SANZ EgAÑa (1941), pp. 84-85; LLORENTE (1856), p. 15.

37 ZARzoso, A. (2007), Medicina para animales en la Cataluña del s. XVIII: una práctica médica plural, Asclepio, 59 (1), pp. 101-130, pp. 102 y 128-130. Según este autor, hubo otros factores a considerar, como la difícil situación de la ganadería en el momento, el escaso nivel científico de los albéitares y la visión negativa de la ganadería por los agraristas y los círculos médicos ilustrados. Especialmente se destaca la falta de interés político en la reforma sanitaria de la política borbónica referente a la sanidad animal. Ello se tradujo en un apoyo inicial a la veterinaria pero después quedó en apoyo aparente. La escasa inversión con una única Escuela en todo el país, a su vez poco dotada, como refleja el autor citado, sobre todo si se compara con los esfuerzos de inversión y reforma administrativa que conllevaron los Reales Colegios de Cirugía, coadyuvaron sin duda a una absorción por supervivencia. Así lo prueba que reunidos Tribunal y Escuela en 1835, aquél no se extingue oficialmente hasta 1847. Es entonces, en un contexto diferente, cuando se apuesta con mayor firmeza desde la administración y se crean dos escuelas adicionales (Córdoba y Zaragoza) permitiendo el relevo y final de la albeitería.

38 IBORRA (1987), pp.75-98. La Planta del Real Tribunal del Protomedicato establecida en 1780 asigna a Protomédicos, Protocirujano y Protofarmacéutico un sueldo de 8.000 reales anuales.

39 AGA, c. ${ }^{\text {a } 32 / 16360 . ~ E l ~ R e g l a m e n t o ~ p r o v i s i o n a l ~ d e ~ l a ~ E s c u e l a ~ d e ~ V e t e r i n a r i a ~ f u e ~ e l a b o-~}$ rado a 7-01-1793 por el Príncipe de Monforte y por el miembro del Consejo de Castilla Domingo Codina, Protectores de la Escuela. Fue aprobado por Real Orden comunicada por el Conde del Campo de Alange al Príncipe de Monforte a 12-02-1793. El cobro de las cantidades asignadas las realizan los cinco Gremios Mayores de Madrid, manteniendo el importe en 
ro, tras el fallecimiento de Fernando VII los cambios políticos y administrativos acaecidos hacen que se supriman la mayor parte de los arbitrios que daban lugar a una suficiente renta ${ }^{40}$. Por su parte, el Tribunal del Protoalbeitarato obtiene sus elevados ingresos a través del importe de los derechos de examen abonados por los aspirantes al título de Maestro herrador y albéitar. La penuria económica de la Escuela y la importante percepción de derechos de examen por parte del Tribunal conducen a la ansiada absorción como vía de financiación para la Escuela. Respecto al interés de los propios examinadores, presentamos datos de uno de sus representantes emblemáticos, el $\mathrm{Di}$ rector Primero Segismundo Malats. El importe de los derechos de examen en 1814 asciende a 700 reales, cuyo desglose, hasta ahora inédito, describe el propio Malats en su Manifiesto ${ }^{41}$ : para los Alcaldes Examinadores, 496 reales, «si son o no excesivos, no lo diré; sí solo que así lo he visto siempre»; para la Real Hacienda por el derecho de media anata, 93 reales; por el sello estampado en el título, 32 reales; por los derechos de asesor, 40 reales; repartiéndose escribiente y portero los 39 reales restantes. Este importe, admitiendo los 400 aspirantes anuales señalados por Nicolás Casas y corroborados por Sanz Egaña ${ }^{42}$, supone unos ingresos para los Alcaldes Examinadores de 200.000 reales anuales, generados con un mínimo esfuerzo por no ser necesario desarrollar ninguna labor docente.

Esta elevada cantidad económica es la razón por la que los Mariscales de la Real Caballeriza quieren mantener vigente a toda costa el Tribunal del Protoalbeitarato, del que son Alcaldes Examinadores, pero la presión que pueden ejercer ante el Rey para imponer su continuidad nos parece insuficiente. Por otro lado, las decisiones políticas no siempre se justifican en la defensa de intereses de una escasa minoría.

La historiografía veterinaria ha soslayado las causas de orden político en la pervivencia del Tribunal ${ }^{43}$. Pretendemos contraponer estas razones, en concreto

depósito, con la obligación de entregar al Contador de la Escuela las cantidades expresadas en los libramientos, firmados por el Director Primero y visados por los Protectores de la Escuela.

40 LlORENTE (1856), p. 14. «Principiaron á faltar los recursos mas indispensables, con tanto mas motivo cuanto las atenciones de la guerra civil todo lo absorbían».

41 Malats, S. (1814), Manifiesto que en contestacion al aviso importante a los albeitares, impreso en esta corte en 24 de Octubre de 1813 por don Antonio Bobadilla, ofrece al publico DON SEGISMUNDO MALATS, Madrid, Imprenta de Repullés, pp. 97-98. Publicación no incluida en la bibliografía veterinaria de Sanz Egaña ni en la obra de Palau Claveras.

42 SANZ Egaña (1941), p. 94.

43 Sanz Egaña responsabiliza a los primeros historiadores veterinarios de no entrar en el fondo del asunto, de no proporcionar ninguna clave sobre este tema, especialmente a Casas y 
la defensa de las antiguas instituciones, como uno de los principales sustentos del Real Tribunal del Protoalbeitarato ${ }^{44}$. Concedemos así un mayor peso a estas motivaciones, asociadas evidentemente a razones económicas y de interés social, que prevalecieron sobre las de tipo técnico o de interés sanitario. Queremos dirigir la atención en especial al papel de árbitro que juega el representante de la institución conservadora, el Caballerizo Mayor.

\section{CONVOCATORIA DE OPOSICIÓN PARA CUBRIR LA PLAZA DE TERCER ALCALDE EXAMINADOR DEL REAL TRIBUNAL DEL PROTOALBEITARATO}

Entre los antecedentes del intento de absorción definitivo de 1835, hay hechos previos que condicionan su desenlace y no han recibido la atención que requieren por parte de los historiadores. El complejo proceso de la provisión de una vacante producida en el Tribunal en 1832 agudiza la pugna entre las instituciones antagónicas y se introduce en el contencioso de la absorción como un eslabón más. El intento de ocupación a título personal de puestos en el Tribunal por parte de los Catedráticos, al margen de los intentos de fusión desde la Escuela, se plantea como vía paralela a la fusión. Esta convocatoria y su desarrollo permiten sacar a la luz los intereses de cada institución y el papel de sus representantes.

Desde 1815 el Real Tribunal del Protoalbeitarato queda formado por el Mariscal de Número que tiene asignado cada uno de los dos Cuarteles ${ }^{45}$, y por

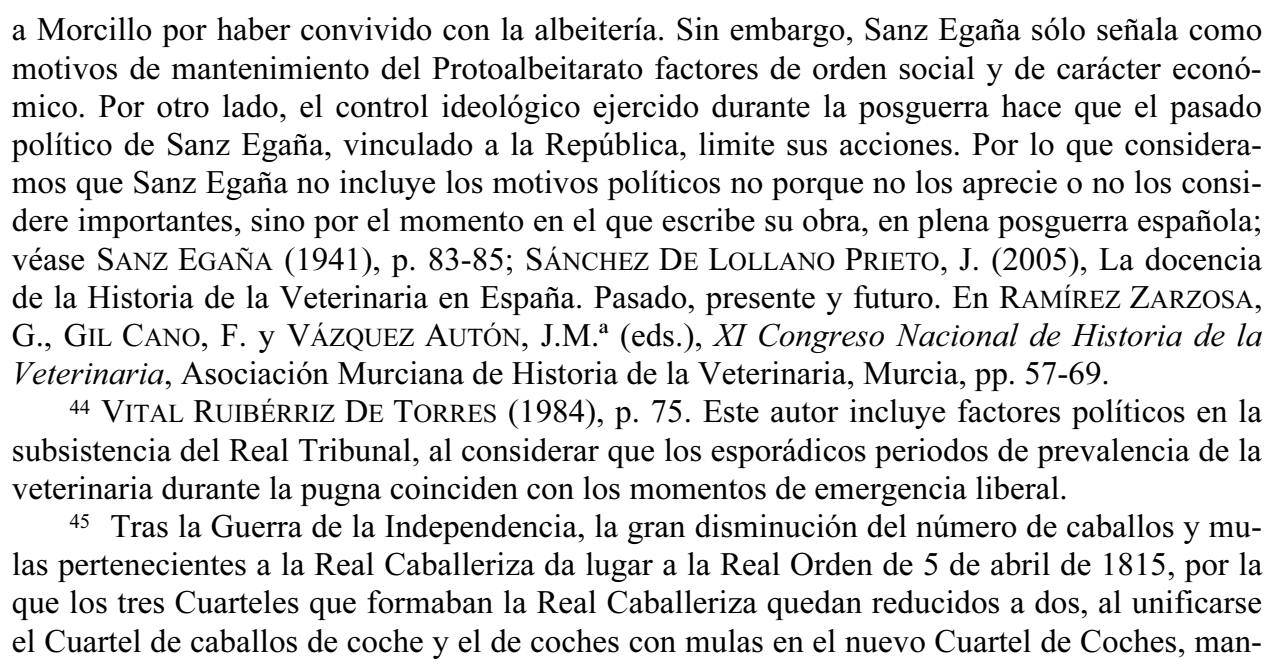


Segismundo Malats, que por Real Orden de 21 de enero de 1800 fue expulsado del servicio activo en la Real Caballeriza, pero mantiene su plaza de Mariscal de Número y, por tanto, de Alcalde Examinador del Real Tribunal del Protoalbeitarato ${ }^{46}$. Tras el fallecimiento de Segismundo Malats el 24 de diciembre de 1826, la plaza de tercer Alcalde Examinador del Tribunal pasa a ser ocupada por el Herrador de Caminos de la Real Caballeriza más antiguo, nombrado Mariscal de Número honorario o supernumerario.

Al producirse el 11 de enero de 1832 el fallecimiento del Mariscal de Número honorario Francisco Reyes Cabero, se presentan dos instancias para ocupar la plaza vacante: la del Herrador de Caminos de la Real Caballeriza José Martínez, veterinario titulado, informada de forma favorable por el Caballerizo Mayor; y la del Mariscal Mayor del Regimiento de Cazadores a caballo de la Guardia Real, Isidro Espada, también veterinario titulado, cuya instancia es apoyada por la Comandancia General de la Guardia Real de Caballería. La resolución final no se decanta por ninguna de las dos partes y por Real Orden de 26 de febrero de 1832 se convoca la, hasta ahora, inédita oposición ${ }^{47}$. Esta convocatoria supone la ruptura con el método tradicional de ascenso, en la que la prevalencia la detenta el más antiguo en la plaza inmediata inferior.

Unos días después de convocada la oposición, Carlos Risueño, Primer Catedrático de la Escuela de Veterinaria desde 1830, cargo equivalente a Director, eleva una instancia al Rey, instancia apoyada por el Duque de Alagón, Protector de la Escuela ${ }^{48}$. Esta solicitud, que no prosperará, representa un

teniéndose el Cuartel de Regalada. El número medio anual de caballos y mulas pertenecientes a la Real Caballeriza es de 1.663 durante el año 1804, de 1.365 durante 1807, viéndose reducido a 251 por el Plan de Servidumbre aprobado a 14-09-1814; véase: SALVADOR VELASCO (2004), pp. 183-186, 197-200 у 259-260.

46 Salvador Velasco, A., Pérez García, J.M. y Sánchez De Lollano Prieto, J. (2006b), Exclusión de Segismundo Malats (c.1747-1826) de la Real Caballeriza. Intervención de Bernardo Rodríguez (c.1756-1819). En Rojo, F., MARTínez, J.M. y FERnÁNDEZ, J.G. (coords.), XXXVII International Congress of the World Association for the History of Veterinary Medicine, León, MIC, pp. 259-264.

47 AGP, Expediente personal de José Martínez, c. ${ }^{\text {a } 3644 / 94 . ~ R e a l ~ O r d e n ~ c o m u n i c a d a ~ p o r ~}$ Mayordomía Mayor al Caballerizo Mayor convocando la oposición, «cuyos aspirantes han de reunir el merito e instruccion suficiente cual se requiere para componer el expresado Tribunal, añadiendose a estas cualidades el de ser adictos en todas epocas a los sagrados e imprescriptibles derechos de S.M.», en Palacio a 26-02-1832.

48 AGP, Reinado Fernando VII, Personal, c. ${ }^{a}$ 271/11. Informe de Protección de la Real Escuela de Veterinaria apoyando la instancia adjunta de D. Carlos Risueño, firmado por el Duque de Alagón y comunicado al Mayordomo Mayor, en Madrid a 9-03-1832. «Siendo la soberana intención de S.M. lograr por medio de la oposicion el profesor mas inteligente y 
nuevo intento de control del Tribunal del Protoalbeitarato por parte de la Escuela de Veterinaria, de momento parcial, pues serían dos los miembros del Tribunal pertenecientes a la Real Caballeriza por sólo uno de la Escuela.

Los siete artículos que contiene la Real Orden de 27 de abril establecen las bases de la oposición a la plaza de Mariscal supernumerario de la Real Caba1leriza, que ejercerá como tercer Alcalde Examinador del Real Tribunal del Protoalbeitarato ${ }^{49}$. El tribunal de la oposición estará formado por los dos Alcaldes Examinadores y por tres Catedráticos de la Escuela de Veterinaria, no determinándose quiénes han de ejercer como Presidente y Vicepresidente de la misma. Esto dará lugar a numerosas fricciones entre ambas instituciones, producidas por el deseo de mostrar la hegemonía de una sobre otra.

Desde la Real Caballeriza, tanto los dos Mariscales de Número, José Victoriano Montero y José Foraster, como el Caballerizo Mayor, Marqués de Bélgida, basan sus solicitudes en el convencimiento de que el nombramiento como Mariscal de Número supone el término de la carrera profesional, ya que «el Tribunal siempre goza de un caracter superior al de la Escuela» ${ }^{50}$.

mejor practico para el servicio de sus Reales Caballerizas se conseguiria este importante fin sin perdida de tiempo con el nombramiento de Risueño».

49 Los ejercicios, tanto teórico como práctico, se desarrollarán en la Escuela utilizando la enfermería de la misma, y los aspirantes deberán haber sido alumnos de la Escuela de Veterinaria de Madrid. Serán los Catedráticos de la Escuela de Veterinaria los que junto con los dos Alcaldes Examinadores del Protoalbeitarato fijen los términos de la convocatoria y el tipo de ejercicios que compongan el examen, así como su duración. Los Mariscales de la Real Caballeriza se muestran en desacuerdo con que los ejercicios de la oposición se desarrollen en la Escuela, tanto por la existencia en la Real Caballeriza Regalada de enfermería bien dotada y con caballerías para los casos prácticos, como por estar ubicado el Tribunal del Protoalbeitarato en una dependencia del mismo edificio. Además, se muestran recelosos ante la valoración política de los Catedráticos, ya que la Real Orden especifica que «los aspirantes han de ser adictos a los sagrados e imprescriptibles derechos de la corona», y a juicio de los Mariscales esto afecta tanto a los Catedráticos que se presenten a la oposición como a los que formen parte del Tribunal de la misma, por lo que de forma maliciosa piden que se designe quién debe reconocer la documentación aportada y cómo actuar «para evitar incidentes desagradables». Los Catedráticos pretenden que todo el proceso se desarrolle como en las oposiciones convocadas para ocupar las plazas de Catedrático, de este modo la oposición se debería realizar en la Escuela, «para poder consultar la Ordenanza que la rige y los antecedentes de las oposiciones»; véase: AGP, Expediente personal de José Martínez, c. ${ }^{\text {a } 3644 / 91 ; ~ A G P, ~ E x p e d i e n t e ~ p e r s o n a l ~ d e ~ J o s e ́ ~ V i c t o r i a n o ~ M o n t e r o, ~ c . ~}{ }^{a}$ 699/5; AGP; Reinado Fernando VII, Personal, c. ${ }^{\text {a }} 271 / 11$.

50 AGP, Expediente personal de José Victoriano Montero, c. ${ }^{a}$ 699/5. Instancia de los Mariscales de Número dirigida al Caballerizo Mayor, apoyada por éste en su informe remitido a Mayordomía Mayor, en Madrid a 31-05-1832. 
Por su parte, la Junta de Catedráticos insta al Duque de Alagón a que sea el Primer Catedrático, Carlos Risueño, quien ostente la presidencia de la oposición, ya que al celebrarse ésta en la Escuela, consideran justo que los Catedráticos mantengan sus derechos ${ }^{51}$. El Duque de Alagón, además, pretende que todo el proceso se resuelva en el menor tiempo posible, para evitar las dilaciones que acertadamente teme que se produzcan por parte de los miembros del Tribunal ${ }^{52}$.

Las solicitudes de ambas instituciones dan lugar a la Real Orden de 19 de agosto de 1832. En ella se determina que los documentos que acrediten a los aspirantes a la oposición como adictos al Rey, serán evaluados por el Caballerizo Mayor y su Secretaría, y en su ausencia por el Alcalde Examinador de mayor antigüedad. También establece que el Presidente de la Oposición será el Caballerizo Mayor, Marqués de Bélgida. Ambas medidas sitúan en clara ventaja al Tribunal sobre la Escuela.

4.1. Enfrentamientos entre Real Caballeriza y Escuela de Veterinaria por poseer el control de la oposición

Una vez más el Duque de Alagón demuestra su gran perseverancia en el mantenimiento de los derechos de la Escuela. El 4 de noviembre de 1832, comunica al Marqués de Bélgida haber puesto en conocimiento de la Junta de Catedráticos que los Mariscales de Número acudirán a la Escuela en el día y hora que se acuerde. Se da por enterado de la resolución que nombra al propio Marqués de Bélgida como Presidente del concurso e informa a éste de haber elevado a la Reina, a través del Ministerio de la Guerra «de quien unicamente depende el Establecimiento de mi cargo», la solicitud de cumplimiento del Artículo 578 de la Ordenanza de la Escuela aprobada en 1827, que especifica que los veterinarios titulados ocuparán las plazas de Mariscal de Número y de Herrador de Caminos de la Real Caballeriza mediante oposición celebrada en la Escuela ${ }^{53}$.

51 Archivo General de la Universidad Complutense de Madrid (en adelante AGUCM), Actas y correspondencia del Protector, año 1832, c. ${ }^{a}$ V/01-006. Acta de 17-05-1832.

52 AGP, Expediente personal de José Martínez, c. ${ }^{\text {a } 3644 / 94 . ~ E n ~ o f i c i o ~ f i r m a d o ~ p o r ~ e l ~ D u-~}$ que de Alagón y comunicado a Mayordomía Mayor, pide que se apremie a los Mariscales en el desarrollo de la convocatoria «para evitar los entorpecimientos que podrían sobrevenir, por las causas que alcanzará facilmente la penetración de V.S.», en Aranjuez a 13-05-1832.

53 AGUCM, Actas y correspondencia del Protector, año 1832, c. ${ }^{a}$ V/01-006. Acta de 811-1832. AGP, Reinado Fernando VII, Caballerizas, c. ${ }^{a}$ 269. Oficio del Duque de Alagón comunicado al Caballerizo Mayor a 4-11-1832. 
La respuesta del Caballerizo Mayor no se hace esperar. En instancia elevada a la Reina dice aceptar lo determinado en la Real Orden respecto a que las pruebas de la oposición se realicen en la Escuela, pero defiende que las sesiones preparatorias se lleven a cabo en el Tribunal del Protoalbeitarato, situado en el mismo edificio de la Real Caballeriza ${ }^{54}$. Son varios los argumentos expuestos para defender su postura, entre ellos, la Real Orden de 19 de agosto por la que se le nombra Presidente de la oposición y que según él, implica que el nombramiento para la plaza de Mariscal de Número es el término de la carrera, por lo que cree justo que sean los Catedráticos los que se trasladen a la Real Caballeriza para así cumplir con el orden de graduación, a cuyo final han llegado los Mariscales y aún no los Catedráticos. Tergiversa las palabras del Protector de la Escuela y retuerce los argumentos por él expresados, de forma que afirma que éste pretende hacerle renunciar a su nombramiento como Presidente de la oposición apoyándose en el Artículo 578 de la Ordenanza de la Escuela, contrariando así la voluntad de la propia Reina expresada en la Real Orden con su nombramiento.

A propuesta del Duque de Alagón, la Junta de Catedráticos elabora en enero de 1833 un informe que recoge las razones que hacen conveniente la unión de Tribunal y Escuela: formación de profesionales instruidos, ingresos económicos suficientes para mantener la Escuela sin recurrir al Erario Público y apertura de nuevas Escuelas de Veterinaria ${ }^{55}$. Interviene en la polémica el Secretario del Despacho de Guerra, del que depende la Escuela de Veterinaria, argumentando su apoyo al Protector ${ }^{56}$. Pero es desde Mayordomía Mayor,

54 AGP, Reinado Fernando VII, Caballerizas, c. ${ }^{\text {a }}$ 269. Instancia del Caballerizo Mayor elevada a la Reina, consta de siete páginas y dos notas adjuntas, en Madrid a 11-11-1832.

55 AGUCM, Correspondencia del Ministerio de Fomento, año 1833, c. ${ }^{a}$ V/01-001. Solicitud de informe a la Junta realizado a 12-01-1833 por el Duque de Alagón. La iniciativa de la idoneidad del momento para solicitar al Rey la reunión de Tribunal y Escuela es, según explicación del Protector, del Contador de la Escuela. Advierte el Duque de Alagón a la Junta que el informe, elaborado al día siguiente, «se haga con el mayor sigilo y reserva, pues conoce muy bien que á no ser asi pudiera encontrar obstaculos de consideración».

56 AGP, Reinado Fernando VII, Caballerizas, c. ${ }^{\text {a }}$ 269. El Secretario del Despacho de Guerra, en oficio comunicado al Mayordomo Mayor a 12-03-1833, se muestra contrario al nombramiento del Caballerizo Mayor como Presidente de la oposición, aunque respeta la Real Resolución, «pero al ver que se trata de destruir una de las prerrogativas de la Escuela, como ya se ha anulado la de que los dos Catedraticos mas antiguos de ella sean individuos del Tribunal del Protoalbeitarato, sobre lo cual me reservo elevar despues a la soberana consideración de S.M. la correspondiente reclamacion, no puedo menos de recurrir ahora a V.E. solicitando una Real declaracion confirmatoria de la que comprende el referido articulo 578», del que según su opinión emana el que el Protector de la Escuela debe ser quien presida la oposi- 
favorable a las tesis de la Real Caballeriza, desde donde en última instancia se informa al Rey. Mayordomía opta por ignorar las solicitudes realizadas desde la Escuela, culpa al Protector por insistir en presidir la oposición como la causa de que ésta no se haya realizado aún, confirma al Caballerizo Mayor como Presidente de la misma y establece que ésta se verifique en la Escuela por estar en ella la enfermería para los casos prácticos, «lo mismo que se ejecutan los ejercicios de cualquier plaza vacante de Medico-Cirujano en el Real Hospital General» ${ }^{57}$.

El tiempo transcurre, el Marqués de Bélgida continua realizando sucesivas consultas aclaratorias que van produciendo el efecto deseado desde la Real Caballeriza, la dilación del procedimiento. El Marqués de Bélgida, Caballerizo Mayor durante prácticamente todo el reinado de Fernando VII, ejerce como defensor de los valores absolutistas frente a los intentos reformistas ${ }^{58}$. Por otro lado, de acuerdo con Zarzoso ${ }^{59}$, no había verdadero interés en desmontar estos argumentos, pues de haber existido voluntad política, hubiesen sido fácilmente modificables ${ }^{60}$.

La pugna entre el Tribunal del Protoalbeitarato y la Escuela de Veterinaria, lo que es lo mismo, entre albéitares y veterinarios, surgida desde el mismo momento de la apertura de la Escuela, se agudiza. El hecho de que, aunque con una preparación muy diferente, ambos tengan como principal función la asistencia clínica y el herrado de los équidos, hace inevitable el constante

ción. Señala como de absoluta necesidad que se conserven los privilegios de la Escuela de Veterinaria, para así promover la formación de veterinarios hábiles que propaguen las enseñanzas recibidas.

57 AGP, Reinado Fernando VII, Caballerizas, c. ${ }^{\text {a } 269 . ~ S e ~ c o m u n i c a ~ d e s d e ~ M a y o r d o m i ́ a ~}$ Mayor la nota en forma de Real Orden al Caballerizo Mayor y al Secretario del Despacho de Guerra, a 4-07-1833. AGUCM, Correspondencia del Ministerio de Fomento, año 1833, c. ${ }^{\text {a }}$ V/01-001. Se complementa con el oficio enviado por el Duque de Alagón al primer Catedrático de la Escuela, dando cuenta de la Real Orden de 2 de agosto comunicada por el Ministro de la Guerra, a 5-08-1833.

58 Ante cada solicitud de unión de ambas instituciones realizada desde la Escuela, el Marqués de Bélgida informa apoyando incondicionalmente los antiguos privilegios de los Mariscales de Número de la Real Caballeriza y Alcaldes Examinadores del Tribunal del Protoalbeitarato, sirviendo de base a las decisiones adoptadas desde Mayordomía Mayor.

59 ZARZOSO (2007), pp. 101-130.

60 Como relata en acertada expresión la Junta de Catedráticos en informe dirigido al Duque de Alagón a 14-01-0833: «el mismo que tuvo facultades para espedirlas [Reales Órdenes y regalías que permiten el mantenimiento del Tribunal del Protoalbeitarato] las tiene para derogarlas»; AGUCM, Correspondencia del Ministerio de Fomento, año 1833, c. ${ }^{\mathrm{a}}$ n. ${ }^{\mathrm{o}}$ V/01-001. 
enfrentamiento. El Duque de Alagón, firme defensor de la Medicina Veterinaria, lo expresa claramente en $1835^{61}$.

\section{El Marqués De Cerralbo, Caballerizo Mayor}

A partir de 1833, el cambio de criterio y la hábil actuación que llevaría a cabo en todo el proceso el nuevo Caballerizo Mayor refuerza nuestro análisis. Fernando de Aguilera y Contreras, XV Marqués de Cerralbo, nació en Madrid el 20 de agosto de $1784^{62}$. Por Real Decreto de 29 de noviembre de 1820, «en atención á sus méritos y conocida adhesión al sistema Constitucional», es nombrado Jefe Político superior de la provincia de Madrid, cargo que lleva unido la Protección de la Escuela Nacional de Veterinaria ${ }^{63}$. Desempeñó este cargo durante breves meses, ya que tenemos constancia de que en mayo de 1821 había sido sustituido. A pesar de haber sido inicialmente un hombre de

61 «Es verdad que desde su creacion han salido de la Escuela muchos profesores, pero el inmenso numero de albeitares que se examinan todos los años ha inundado España, creando en cada uno de ellos un enemigo encarnizado de todos los discipulos de aquella, y de aquí ha nacido la lucha escandalosa que constantemente ha existido entre el Tribunal y la Escuela, entre los albeitares y los veterinarios»; véase: DuQue DE ALAGón (1835), Observaciones del Protector de la Real Escuela de Veterinaria, sobre el dictamen de la comisión de lo interior, relativo al presupuesto de su establecimiento y al Tribunal del Protoalbeitarato, Madrid, Imprenta de Don Pedro Sanz, pp. 5-6.

62 AGP, Expediente personal del Marqués de Cerralbo, c. ${ }^{a}$ 234/14. Fue nombrado Gentilhombre de Cámara por Real Orden de 14-08-1803. Al producirse el fallecimiento del Duque de Híjar, el Marqués de Cerralbo fue nombrado por Real Orden de 18-04-1818 para presidir diariamente el Gabinete Físico-Químico existente en el Real Palacio, del que el Infante D. Carlos era Protector. Enciclopedia Universal Ilustrada Europeo-Americana (1991), Madrid, Espasa-Calpe, p. 1318. El Marqués de Cerralbo fue nombrado en 1819 embajador extraordinario ante el Rey de Sajonia con ocasión del matrimonio de Fernando VII con la Princesa Amalia de Sajonia, en cuya ceremonia representó al Rey de España, siendo el encargado de acompañarla a Madrid y pagados por él los cuantiosos gastos ocasionados. Imágenes históricas del Senado, sign: HIS-0116-07, www.senado.es (consultado en diciembre de 2007). Fue nombrado Prócer del Reino en la legislatura 1834-35. Prestó juramento como tal a 5-09-1834, en el Real Sitio de El Pardo por encontrarse allí desplazado acompañando a la Reina como Caballerizo Mayor. Destacamos entre sus distinciones: Caballero de la insigne Orden del Toisón de Oro, de la Gran Cruz de Carlos III y de la Orden Militar de Alcántara.

63 AGUCM, Actas y correspondencia del Protector, c. ${ }^{a}$ V/01-036. Al ser nombrado Consejero de Estado Miguel Gayoso de Mendoza, anterior Jefe Político superior de la provincia de Madrid, es nombrado el Marqués de Cerralbo para sustituirlo. Comunicado de Real Orden al Director Primero de la Escuela, Segismundo Malats, en Madrid a 04-12-1820. 
confianza de Fernando VII, su adscripción a las filas liberales le apartó de todo puesto de responsabilidad en torno al Rey ${ }^{64}$. Tras el fallecimiento de Fernando VII, los cambios en los cargos de confianza se suceden, inicialmente se le restituye la llave de Gentilhombre de Cámara con ejercicio, manteniendo la antigüedad en el empleo desde su primitivo nombramiento. El 12 de octubre de 1833 es destituido el Marqués de Bélgida como Caballerizo Mayor, siendo nombrado en su lugar por Real Orden de ese mismo día el Marqués de Cerralbo ${ }^{65}$.

Llegó a la Real Caballeriza con la intención de mejorar la gestión y para ello perseguirá disminuir los gastos y mejorar el servicio prestado. Cuenta a su favor con el conocimiento previo de la burocracia de Palacio, por su experiencia como responsable de las compras del Gabinete Físico-Químico, y el de los problemas que impiden avanzar a la Ciencia Veterinaria, por su destino como Protector de la Escuela. A ello se debe sumar su gran capacidad de trabajo y perseverancia ${ }^{66}$.

El Marqués se decantó por la veterinaria como atestigua su informe de 1834, que analizamos en detalle. Por otro lado, la trayectoria histórica de los

64 AGP, Reinado Fernando VII, Caballerizas, Personal, c. ${ }^{a}$ 334. Al restablecerse el absolutismo, Fernando VII dicta en Andújar, a 31 de octubre de 1823, un Real Decreto con las personas que a partir de ese día deberán dejar de prestar servicio en la Real Casa; incluido en la lista y formando parte de la comitiva que acompaña al Rey desde Cádiz a Madrid, está el Marqués de Cerralbo, que es separado del cargo de Gentilhombre de Cámara y anulada la tenencia de la llave que lleva aparejada su destino: «he tenido a bien separar de mi Servidumbre los sujetos contenidos en la adjunta lista, y quiero que se guarde el mayor sigilo hasta que esten comunicadas todas las ordenes, en las que no se insertara este Decreto. Los sujetos separados, y que vengan en la comitiva, continuaran hasta Madrid y alli se les comunicara la orden».

65 AGP, Expediente personal del Marqués de Cerralbo, c. ${ }^{a}$ 234/14. Jura el Marqués de Cerralbo la plaza en manos del Conde de Torrejón, Mayordomo Mayor, a 20-10-1833. Comenzando a percibir 60.000 reales de sueldo anual y 20.000 reales más para mantenimiento del Tren asignado, descontándosele los dos primeros meses de sueldo, así como la media anata, durante los doce meses siguientes.

66 AGP, Fondo RCA, legajo 318.1. Elaboró, entre otras, una Instrucción destinada a los Mariscales de Número, que entró en vigor a 1-06-1836. AGP, Reinado Isabel II, Medicina y Farmacia, c. ${ }^{a} 2 / 22$. A pesar de la oposición del Boticario Mayor, logró que de forma efectiva por Real Orden de 7-09-1836 comenzase la elaboración y dispensación de medicamentos por la Real Botica con destino al ganado de la Real Caballeriza, siempre a través de prescripciones realizadas por los Mariscales de Número. AGP, Administrativa, Reglamentos, legajo 1114. Realizó un minucioso Proyecto de Reglamento de la Real Caballeriza, remitido a Mayordomía Mayor a 1-05-1838. A las siete y treinta y cinco de la tarde del día siguiente se produjo el fallecimiento del Marqués de Cerralbo, lo que paralizó los trámites para su aprobación. 
sucesivos intentos de absorción, siempre fallidos, hizo que al margen de la absorción planteada de forma oficial, a resultas de una serie de factores que analizaremos, concibiera un plan alternativo a través de una contrata.

\subsection{Informe del Marqués de Cerralbo a favor de la Ciencia Veterinaria}

En noviembre de 1833, un mes después de su nombramiento como Caballerizo Mayor, desde Mayordomía Mayor se requiere al Marqués de Cerralbo para que emita su opinión sobre la convocatoria de oposición a Mariscal supernumerario. Manifiesta conocer el expediente y estar de acuerdo en realizar una oposición para cubrir la plaza, porque con el método tradicional de promoción por rigurosa antigüedad no le parece posible formar buenos profesionales. Se muestra además proclive a que se instruya el oportuno expediente para evaluar si el Real Tribunal del Protoalbeitarato debe continuar formado por los tres Mariscales de la Real Caballeriza o que los Catedráticos de la Escuela de Veterinaria formen también parte de él «y asi proporcionar a la Ciencia Veterinaria los adelantos de que es susceptible ${ }^{67}$.

Sucede entretanto un hecho al que la veterinaria ha concedido una importancia capital en la absorción del Tribunal, argumentando con gran énfasis el papel desempeñado por los profesores de la Escuela. Se trata de la visita que con fecha 9 de enero de 1834 realiza la Reina Gobernadora, M. ${ }^{a}$ Cristina de Borbón, a la Escuela de Veterinaria de Madrid. En ella adquiere el compromiso ante el Duque de Alagón y los Catedráticos de llevar a cabo la unión del Tribunal del Protoalbeitarato y de la Escuela ${ }^{68}$.

De modo paralelo, Mayordomía Mayor aprecia síntomas de cambio en el informe del Marqués de Cerralbo que apoyan el compromiso adquirido por la Reina Gobernadora, por lo que su propuesta es bien recibida y se le conmina a 20 de enero de 1834 «para que sin demora proponga a S.M. el modo de formarse el Tribunal donde sean examinados los que aspiren a ser profesores

67 AGP, Reinado Isabel II, Veterinaria, c. ${ }^{\text {a }} 1 / 38$. Desde Mayordomía Mayor se solicita informe al Caballerizo Mayor mediante Real Orden comunicada a 23-11-1833. El informe del Marqués de Cerralbo es apoyado desde la Secretaría de la Real Caballeriza y comunicado a Mayordomía Mayor a 7-12-1833

68 Rodríguez Garrido, N. y Salvador Velasco, A. (2007), Visita de la Reina Gobernadora a la Real Escuela: consideraciones en torno a su papel en la absorción del Tribunal del Protoalbeitarato. En Asociación Catalana de Historia de la Veterinaria (coord.), XIII Congreso Nacional de Historia de la Veterinaria, Girona, pp. 116-120. 
de Veterinaria» ${ }^{69}$. Sin embargo, ese mismo día, a modo de contrasentido, otra Real Orden comunicada al Caballerizo Mayor y al Protector de la Escuela de Veterinaria establece que sean los Alcaldes Examinadores del Tribunal del Protoalbeitarato, tomando como base los ejercicios de las oposiciones a las plazas de Catedrático de la Escuela de Veterinaria, quienes elaboren los términos de la convocatoria y la clase y duración de los ejercicios, y que transcurridos los cuarenta días que se dan de plazo propongan los tres Catedráticos que como Censores intervendrán junto a ellos en la oposición ${ }^{70}$.

Esta última Real Orden, por intervención del Marqués de Cerralbo como en su posterior informe se deduce, no tendrá ningún desarrollo. Transcurridos los cuarenta días indicados en la misma, los Catedráticos de la Escuela de Veterinaria elevan una instancia a la Reina Gobernadora proponiendo una nueva fórmula para cubrir la vacante de Alcalde Examinador, «para evitar los abusos y perjuicios que la ignorancia y malicia de los Mariscales ocasionaban a la Real Caballeriza», solicitan que las plazas de Mariscal de Número de la Real Caballeriza sean ocupadas por los Catedráticos de la Escuela por orden de rigurosa antigüedad, con retención de sus respectivas Cátedras, por lo que la actual vacante sería ocupada por el más antiguo ${ }^{71}$. Este nuevo intento de control del Tribunal por los Catedráticos, con cuya motivación el Marqués de Cerralbo expresará su conformidad aunque no con la solución propuesta, tampoco prosperará.

En mayo de 1834, el Marqués de Cerralbo presenta el informe que le había solicitado Mayordomía Mayor cuatro meses antes ${ }^{72}$. Es un extenso trabajo de veintisiete páginas en el que demuestra su conocimiento sobre la formación científica que proporciona la veterinaria y su convencimiento de la superioridad de ésta sobre la vetusta albeitería, a la que considera de desfasada prepa-

69 AGP, Reinado Isabel II, Veterinaria, c. ${ }^{a} 1 / 38$. Por Real Orden comunicada por Mayordomía Mayor se solicita un segundo informe al Caballerizo Mayor, a 20-01-1834.

70 AGP, Reinado Isabel II, Veterinaria, c. ${ }^{\text {a }} 1 / 38$. Real Orden comunicada por Mayordomía Mayor al Caballerizo Mayor, al Contador General de la Real Casa y al Protector de la Real Escuela de Veterinaria, a 20-01-1834. AGUCM, Correspondencia del Ministerio de Fomento, año 1834, c. ${ }^{a}$ V/01-017. El Duque de Alagón comunica la Real Orden al primer Catedrático para que lo ponga en conocimiento de la Junta, en Madrid a 25-01-1834.

71 AGP, Reinado Isabel II, Agregado, Personal, c. ${ }^{a} 1 / 19$. Instancia elevada a la Reina, realizada por los Catedráticos de la Real Escuela de Veterinaria en enero de 1834. En anotación marginal, a 11-03-1834 se pide informe de la misma al Caballerizo Mayor.

72 AGP, Reinado Isabel II, Veterinaria, c. ${ }^{a} 1 / 38$. Informe dirigido a la Reina Gobernadora y firmado por el Marqués de Cerralbo, en Aranjuez a 19-05-1834. 
ración y a la que se debe privar de sus antiguos privilegios ${ }^{73}$. Propone la realización de un Reglamento «modificando las viciosas ordenanzas actuales de la Escuela Veterinaria», en cuya elaboración participen Profesores veterinarios, el Ministerio de Fomento por ser de quien depende la Dirección de Estudios y el propio Caballerizo Mayor. Esta propuesta implica la pérdida de la dependencia militar de la Escuela de Veterinaria, tanto por dejar de depender del Ministerio de la Guerra como por la desaparición de la Secretaría de la Protección de la Escuela, a cuyo frente se encuentra el militar propuesto por la Junta de Caballería, con un coste anual de 60.000 reales. Sería sustituido por el propio Caballerizo Mayor que, sin recibir sueldo, haría la misma función ${ }^{74}$.

Presenta un nuevo método de financiación para la Escuela, basado en los derechos de examen de los aspirantes al título de Maestro herrador y albéitar, cuyo importe, al ser realizado el examen por los Catedráticos, sería percibido por la Escuela ${ }^{75}$. También emite su opinión sobre el hecho de que los Catedrá-

73 En su informe, el Marqués de Cerralbo deja asentada la necesidad de que los albéitares se sometan a examen para obtener su título, que deberá realizarse por «examinadores de carrera cientificamente concluida, practica reflexiva, y de opinion y concepto merecidos», cualidades que según él no poseen los miembros del Protoalbeitarato, con los que es muy duro en sus opiniones: «los actuales Alcaldes deben sin duda desecharse como examinadores de todos los de su ramo, por ser puramente practicos». Y continúa abogando por su destitución, «ninguna duda parece ocurre en desechar de este cargo a los Alcaldes nombrados segun costumbre, en proponer a V.M. le tengan los Catedráticos de la Escuela Veterinaria». Afirma sorprenderse por el hecho de que «el actual Proto-albeiterato establecido en el año de 1.500 sin Reglamento alguno sin bases como Gefe de todos los Albeitares, haya podido mantenerse sin modificacion ninguna hasta el dia de hoy». Teniendo además en cuenta que, desde la puesta en funcionamiento de la Escuela de Veterinaria las controversias entre ambas instituciones han sido numerosas, resolviéndose siempre a favor del Protoalbeitarato «por el solo interes y la costumbre». Califica como «lucro desmesurado» los ingresos de los Alcaldes Examinadores, ganancia basada en «privilegios antiguos y costumbre embegecida».

74 Para el Marqués de Cerralbo la dependencia militar de la Escuela de Veterinaria es también causa del retraso de la Ciencia Veterinaria. opina que si la Escuela, «como todas las del arte de curar», hubiese dependido del Ministerio de Gracia y Justicia, con el Caballerizo Mayor como Jefe, no hubiesen prevalecido ni los intereses de los empleados militares de la Escuela ni los de los Protoalbéitares, «y las Escuelas de Veterinaria estarían extendidas por España dando los frutos apetecidos». A modo de ejemplo de buen funcionamiento y «por razón de analogia» cita la Escuela de Medicina. Refiere al respecto: «La Escuela Veterinaria llora su dependencia del Cuerpo militar, y desea con ansia libertarse de este yugo oneroso pretendiendo y clamando que su Gefe u órgano en comunicación con el Ministerio de Fomento sea el Caballerizo Mayor de V.M.».

75 Estima el beneficio anual así obtenido en 218.135 reales, importe al que añadiendo algún pequeño arbitrio, considera suficiente para el mantenimiento de la Escuela y para abrir las Escuelas de Veterinaria que cree tan necesarias en España. 
ticos de la Escuela de Veterinaria hayan realizado numerosos escritos proponiendo ser ellos mismos los que únicamente ejerzan como Alcaldes Examinadores del Tribunal del Protoalbeitarato. Curiosamente, al Marqués de Cerralbo las razones que alegan los Catedráticos no le parecen concluyentes ${ }^{76}$.

Asimismo, se muestra abierto a establecer contactos con otros establecimientos equivalentes del extranjero, que permitirían el conocimiento de los avances experimentados en las diferentes especies de ganado, lo que redundaría tanto en el Real beneficio como en el general de la Nación.

Con la designación del Caballerizo Mayor como responsable de la Protección de la Escuela de Veterinaria, el Marqués de Cerralbo quiere lograr la interconexión entre la que denomina Junta Superior Directiva de la Facultad Veterinaria, la Escuela de Veterinaria y la Real Caballeriza. Concluye su informe concretando ocho propuestas, de las que resaltamos:

- Los examinadores de los Maestros albéitares y de los Profesores veterinarios serán los Catedráticos de la Escuela de Veterinaria y un miembro del Tribunal del Protoalbeitarato, institución que pasaría a denominarse Junta Superior Directiva de la Facultad Veterinaria.

- Que sea la Escuela de Veterinaria quien, en lugar de los Alcaldes Examinadores del Protoalbeitarato, perciba los derechos de examen, sirviendo estos ingresos para el fomento de la Facultad Veterinaria.

- Debido a la escasa formación de la mayor parte de los albéitares españoles y su gran importancia para el pueblo, se elaborará un Reglamento de esta Facultad, realizado por un Cuerpo Facultativo del que será Jefe el Caballerizo Mayor.

- Este Cuerpo Facultativo o Junta Superior Directiva de la Facultad Veterinaria estará formado por los dos actuales miembros del Protoalbeitarato y los tres primeros Catedráticos de la Escuela de Veterinaria.

- Además de solicitar la derogación de la convocatoria de oposición en curso, dos de las propuestas hacen referencia a la absorción de cargos por parte del Caballerizo Mayor. Al ser nombrado Protector de la Es-

76 Afirma que no son los únicos dotados de talento eminente y superior entre los de su profesión, que la larga carrera de que se jactan pueden poseerla veterinarios que, ejerciendo ajenos a las Cátedras, progresan en teoría y en práctica y estudian para aumentar sus conocimientos, haciéndose así acreedores a ocupar la plaza de Alcalde Examinador «de preferencia a cualquier Catedratico sin otra disposición ni talento estraordinario, que el unico e indispensable a los ejercicios hechos para obtener la Catedra y esplicar en su asignatura por el autor testual correspondiente». 
cuela y Jefe de la Junta Superior Directiva de la Facultad Veterinaria, sin dotación económica alguna, actuaría como interlocutor entre el Ministerio de Fomento y Mayordomía Mayor de la Real Casa.

En el caso de que sus propuestas sean aceptadas, el Marqués de Cerralbo presenta, además, un listado con catorce medidas secundarias que estarían vigentes mientras se elaborara el Reglamento por él solicitado. Entre estas medidas secundarias destacamos tres por su intencionalidad: en una de ellas expone que «a proporcion que bayan faltando los individuos de esta Junta» se suprimirán sus plazas hasta quedar reducidas a tres; en otra, determina que mientras se aprueba el propuesto Reglamento, si se produjera alguna vacante, ésta será ocupada por los Catedráticos o por algún destacado profesional; y en la última, propone que los cinco miembros de la Junta Superior Directiva ejercerán como Mariscales de la Real Caballeriza. Estas tres medidas están claramente destinadas a potenciar a los Catedráticos de la Escuela frente a los Alcaldes Examinadores del Protoalbeitarato ${ }^{77}$. La finalidad de todo el contenido del informe se centra en la absorción del Real Tribunal del Protoalbeitarato por una Escuela de Veterinaria reconvertida en institución civil, permitiendo a esta última ostentar la hegemonía de la enseñanza de la Medicina Veterinaria en España.

Una vez recibido el informe del Marqués de Cerralbo, desde Mayordomía Mayor se solicita un dictamen sobre su contenido a la Junta de Gobierno de la Real Casa. Dos meses después, la Junta de Gobierno manifiesta en un escueto informe no comprender el objeto de los cambios propuestos, centrándose únicamente en la denegación de la solicitud del Caballerizo Mayor de asumir la Protección de la Escuela ${ }^{78}$. No sólo no se aprueba ninguna de las propuestas, sino que ni siquiera son discutidas o rebatidas. Nuevamente el Tribunal del Protoalbeitarato vence en su pugna con la Escuela de Veterinaria. Sin

77 La primera de ellas se encamina a la eliminación de las dos plazas ocupadas por los actuales Alcaldes Examinadores a medida que se produzca su fallecimiento. La segunda asegura que durante el periodo de transición, a la vacante que pudiera producirse en el Tribunal del Protoalbeitarato, no promocione el Herrador de Caminos más antiguo de la Real Caballeriza. Y la última, a que los tres Catedráticos miembros de la Junta ejerzan como Mariscales de la Real Caballeriza como ya lo hacen los dos Alcaldes Examinadores, de forma que cuando estas dos últimas plazas desaparezcan sean los Catedráticos los únicos Mariscales de la Real Caballeriza.

78 AGP, Reinado Isabel II, Veterinaria, c. ${ }^{a} 1 / 38$. Desde Mayordomía Mayor se solicita informe a la Junta de Gobierno de la Real Casa a 3-08-1834. El informe de la Junta de Gobierno es remitido a Mayordomía Mayor a 18-10-1834. Desde ésta se comunica la Real Orden denegatoria al Caballerizo Mayor a 1-11-1834. 
embargo, las medidas contenidas en el informe del Marqués de Cerralbo se irán paulatinamente desarrollando hasta lograr la hegemonía de la Ciencia Veterinaria.

Únicamente escapó a su acertada estrategia de renovación veterinaria su propuesta de mantenimiento de la relación entre la Real Caballeriza y la Escuela de Veterinaria, a través de la vinculación del Caballerizo Mayor a ambas instituciones. No obstante, como analizamos en el punto 5.5, supo subsanar este aspecto.

La negativa respuesta de la Junta de Gobierno de la Real Casa a la propuesta de fusión entre Tribunal y Escuela realizada por el Marqués de Cerralbo, se produce unos días después de dictarse la Real Orden de 1 de octubre de 1834, que ordena la creación de la Comisión encargada de proceder a la redacción del Reglamento a observar una vez producida la reunión de ambas instituciones ${ }^{79}$. Se prefiere esperar a la resolución consensuada por una comisión $^{80}$ que aceptar la decidida propuesta personal del Marqués de Cerralbo.

79 AGUCM, Correspondencia del Ministerio de Fomento, c. ${ }^{a}$ V/01-017. Inicialmente la Comisión estaba formada por D. Antonio Sandalio de Arias, Inspector General de Montes, Dr. D. Raimundo Durán, Secretario de la Real Junta Superior gubernativa de Medicina y Cirugía, y Dr. D. Mariano Delgras, miembro de la Academia de Medicina. A 15 de octubre dimite Durán alegando motivos de salud, siendo sustituido por D. Antonio Moreno, Vocal de la Real Junta Superior de Farmacia y segundo Boticario de Cámara.

80 El Duque de Alagón atribuye al recién creado Ministerio de Fomento la iniciativa de poner en marcha la Comisión, aunque la documentación oficial apunta al propio Duque de Alagón como promotor. DuQue De AlaGón (1835), pp. 6-7. «En honor a la verdad, a no ser por la creacion del Ministerio de Fomento nada hubiera conseguido, pero este Ministerio promovió la Real Resolucion de $1^{\circ}$ de Octubre de 1834 , por la que la Reina Gobernadora se sirvio mandarse procediese inmeditamente a la redaccion del Reglamento que ha de observarse, verificada que sea la reunion de ambos establecimientos». Si bien, según la Real Orden comunicada por el Ministro del Interior al Protector, es consecuencia del expediente instruido por la solicitud de reunión de Tribunal y Escuela solicitada por el propio Duque de Alagón; AGUCM, Correspondencia del Ministerio de Fomento, c. ${ }^{a}$ V/01-017. Sin embargo, las propuestas presentadas por la Comisión no van en la dirección deseada por el Duque de Alagón, en sus Observaciones realizadas a 26 de enero de 1835 se muestra en desacuerdo con algunas de ellas, porque considera que son contrarias a los intereses de la Escuela. 


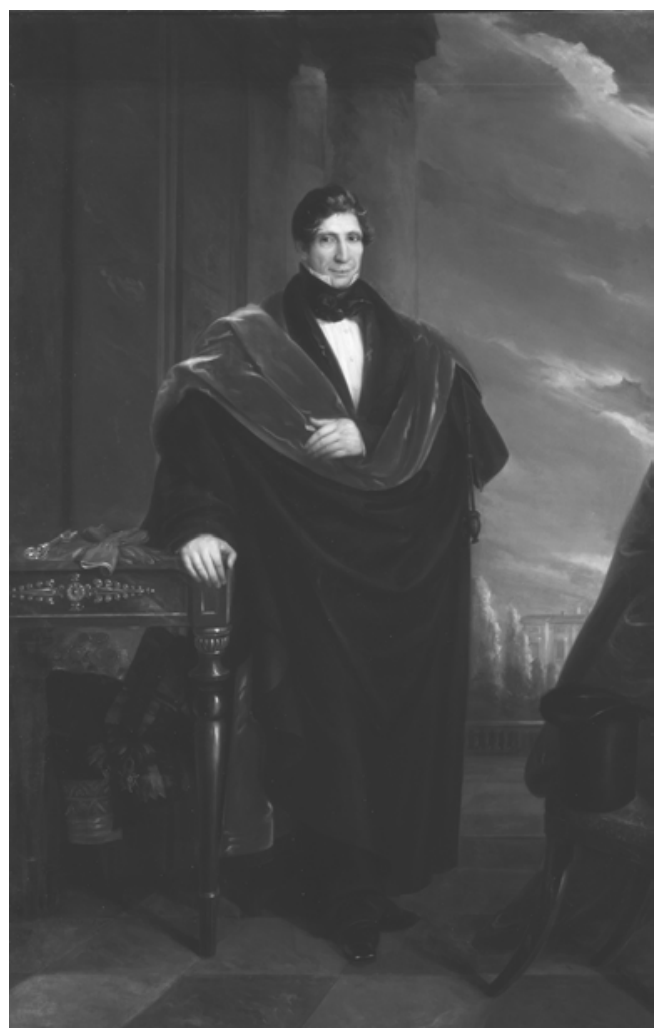

Retrato de don Fernando de Aguilera y Contreras, XV Marqués de Cerralbo. Óleo sobre lienzo realizado por Valentín Carderera en 1833. Sobre el hombro izquierdo se aprecia la fusta, atributo representativo del cargo que ostenta como Caballerizo Mayor. Museo Cerralbo, Madrid.

5.2. El papel del Marqués de Cerralbo en el nombramiento de los Catedráticos de la Escuela de Veterinaria como Mariscales de Número de la Real Caballeriza y Alcaldes Examinadores del Real Tribunal del Protoalbeitarato

El análisis tradicional de la absorción del Tribunal del Protoalbeitarato por la Escuela de Veterinaria no refleja en su real dimensión la compleja situación creada y otorga el mérito de su resolución principalmente a los Catedrá- 
ticos de la Escuela ${ }^{81}$. Aunque Sanz Egaña apunta que de modo indirecto y subrepticio se logró la anhelada absorción, el proceso no ha sido debidamente investigado. En efecto, la solución efectiva a la absorción del Tribunal vendría de la mano de la formalización de una contrata con la Real Caballeriza. Los cinco Catedráticos de la Escuela de Veterinaria pasan a ser Mariscales de Número de la Real Caballeriza el 24 de febrero de 1835, al ser aprobada por la Reina Gobernadora la contrata suscrita por éstos con el Caballerizo Mayor, Marqués de Cerralbo. Poco después serán nombrados Alcaldes Examinadores del Tribunal del Protoalbeitarato.

El Marqués de Cerralbo, represaliado por Fernando VII por su condición de liberal, cuenta con la confianza de la Reina Gobernadora y con su anuencia en las reformas emprendidas, de ningún modo posibles sin el Real apoyo. La contrata promovida por el Marqués de Cerralbo es un subterfugio para no esperar a la resolución final de la Comisión creada para redactar el Reglamento de unión entre la Escuela y el Tribunal, que puede decantarse a favor de éste último como se había venido produciendo en los litigios anteriores entre

81 Casas, N. y SAmpedro, G. (15-05-1845), Necrología de Don José Maria de Estarrona, Boletín de Veterinaria, 5, p. 73. Escriben ambos Catedráticos en la necrológica a su compañero: «fue nombrado a 27 de Marzo de 1835 Mariscal de Número de Reales Caballerizas, por el Caballerizo Mayor, y previa la aprobación de S.M.». Damos explicación a esta fecha en el Apartado 5.3. LlORENTE (1856), p. 15. Escribe al respecto: «de resultas de la peticion hecha por los catedráticos á la gobernadora del reino, $\mathrm{D}^{\mathrm{a}} \mathrm{M}^{\mathrm{a}}$ Cristina, en una visita que hizo á la Escuela en 1834, el Tribunal del Protoalbeiterato se suprimió, incorporándole á la Escuela, cuyos catedráticos habian de desempeñar las plazas de las caballerizas». SANZ EGAÑA (1941), p. 286-289. Complementa este acontecimiento: «en tanto que la Comisión reúne antecedentes y redacta su informe, los Catedráticos de la Escuela, que tan bien impresionados quedaron de la visita de la Reina Gobernadora, consiguen en 27 de marzo de 1835 ser nombrados mariscales de las Reales Caballerizas, nombramientos, como todos los anteriores en estos cargos, expedidos por el caballerizo mayor de Palacio». Forma y fecha del acontecimiento son recogidos por Sanz Egaña, aunque sin citarlos, de Nicolás Casas y Guillermo Sampedro. Estos datos han sido repetidos por diversos autores, si bien, Sanz Egaña aclara en la nota 9 al Capítulo III que no ha conseguido ver la Real Cédula original de los nombramientos a favor de los cinco Catedráticos. SANZ EgAÑA, C. (1-03-1942), Carlos Risueño y Mena (1778-1847), Boletín de Ciencia Veterinaria, 43, p. 149. Nuevamente Sanz Egaña incide sobre su explicación anterior aportando nombres concretos. «En 1835 no se logró una suspensión total del Protoalbeitarato, mediante una hábil estratagema inspirada por Casas, dirigida por Risueño y secundada por los cinco catedráticos: Se apoderaron del Proto-albeitarato de modo indirecto, los cinco profesores titulares de la Escuela fueron nombrados, con anuencia de Su Majestad, mariscales de las Reales Caballerizas destituyendo a los dos que existían. De esta forma un tanto extraña la Escuela se incorporó al Proto-albeitarato». 
ambas instituciones. Como ya se produjo en la persona de Segismundo Malats, con la contrata suscrita tiene lugar nuevamente la vinculación entre Real Caballeriza, Escuela de Veterinaria y Tribunal del Protoalbeitarato, esta vez en la figura de los Catedráticos ${ }^{82}$. El ansiado control del Tribunal del Protoalbeitarato por la Escuela de Veterinaria, realizado a través de la Real Caballeriza, se produce sin esperar a la resolución de las propuestas de la Comisión creada al efecto.

La Real Orden que debía aprobar la contrata debió ser interpretada como una mera formalidad por el Marqués de Cerralbo, únicamente necesaria para promulgar la Orden de destitución de los anteriores Mariscales. Tan seguro estaba de su aprobación que de hecho durante todo el mes de febrero fue el Catedrático y Director de la Escuela, Carlos Risueño, quien realizó la asistencia clínica y el herrado del ganado de la Real Caballeriza ${ }^{83}$. Oficialmente los

82 El motivo por el que no existe ninguna referencia a los nombramientos de los Catedráticos como Mariscales de Número de la Real Caballeriza en la Sección de Expedientes personales del Archivo General de Palacio, hecho que causó extrañeza en Sanz Egaña, es porque la única vinculación de los Catedráticos con la Real Caballeriza se produce a través de una contrata, por la que se comprometen a realizar las obligaciones profesionales de los Mariscales de Número a cambio de un precio establecido. Es decir, no pertenecen a la Planta de la Real Caballeriza, ni hay toma de juramento de la plaza en manos del Caballerizo Mayor, ni tienen asignado sueldo alguno. Históricamente el nombramiento oficial como Mariscal de Número conlleva la asignación de un sueldo a percibir de la Real Caballeriza, que es el menor de los estipulados a categoría alguna de sus dependientes; esto es debido a la mayor consideración que los Mariscales tienen como Oficiales de manos que como profesionales sanitarios, por lo que la mayor parte de sus ingresos provienen de la contrata que mantienen con la Real Caballeriza, en la que se establecen unas determinadas cantidades a percibir por cada caballo y mula herrado y por cada acto profesional realizado; la contrata compensa así el reducido sueldo asignado, algo que no ocurre ni con Médicos ni con Boticarios. En cambio, según la contrata firmada por el Caballerizo Mayor y los Catedráticos, éstos no tienen asignado sueldo alguno y perciben por la asistencia clínica y el herrado de cada caballo y mula 14 reales, no recibiendo ninguna cantidad suplementaria por la realización de cada acto profesional como se producía con anterioridad, siendo abonado por la Real Caballeriza el importe de los medicamentos y productos extraoficinales necesarios para la precisa asistencia; véase: SALVADOR VELASCO Y ANDRÉS TURRIÓN (2005), pp.149-155.

${ }^{83}$ Queda corroborado al presentar la correspondiente cuenta de gastos al finalizar ese mes, en concreto fueron tres las cuentas presentadas por Carlos Risueño por la asistencia clínica y el herrado durante el mes de febrero, que suman un importe de 3.850 reales; véase: AGP, Reinado Isabel II, Cuentas Generales, Caballerizas, c. ${ }^{a} 32$. Los cinco Catedráticos de la Escuela de Veterinaria de Madrid que ejercen como Mariscales de Número durante los catorce meses que se mantiene en vigor la contrata, se van alternando mensualmente en sus obligaciones en la Real Caballeriza y en la asistencia a las Jornadas a los Reales Sitios acompañando a 
Catedráticos pasan a ser Mariscales de la Real Caballeriza el 24 de febrero de 1835 al ser aprobada por Real Orden la contrata suscrita con el Caballerizo Mayor, aunque desde el 1 de febrero desempeñaban oficiosamente sus obligaciones.

Por Orden del Caballerizo Mayor de 26 de febrero de $1835^{84}$, dos días después de ser aprobada por la Reina M. ${ }^{a}$ Cristina la contrata con los Catedráticos, se produce la radical destitución de los dos Mariscales de Número que hasta ese momento ejercen en la Real Caballeriza ${ }^{85}$, José Victoriano Montero ${ }^{86}$ y José Foraster ${ }^{87}$.

la Reina; véase: SALVAdOR VELASCo (2004), pp. 366-370. La asistencia a las Jornadas impide a los Catedráticos impartir la asignatura correspondiente en la Escuela y esta ausencia es acreditada por el Catedrático ante el Protector, que concede permiso quincenal o mensual para que acuda al Real Sitio en el que se realiza la Jornada, nombrando en el mismo oficio al Catedrático que impartirá la asignatura durante la ausencia; véase: AGUCM, Correspondencia del Ministerio de Fomento, c. ${ }^{a}$ V/01-016.

84 La Orden explica claramente el motivo de la destitución: «como consecuencia de la contrata celebrada el 29 de Enero ultimo con los cinco Catedraticos de la Real Escuela de Veterinaria de Madrid para la asistencia, herrado y curacion del ganado de la Real Caballeriza aprobada por S.M. a 24 de Febrero del mismo año». Son cesados en sus funciones profesionales y en el cobro de los 2.000 reales anuales que perciben como sueldo, que se les abonan hasta el final del mes de febrero; véase: SALVAdOR Velasco (2004), pp. 273-278.

85 Ambos nombramientos como Mariscales de Número de la Real Caballeriza se habían producido por Orden del Caballerizo Mayor comunicada al Rey a través de Mayordomía Mayor, realizándose la toma de juramento de la plaza en manos del propio Caballerizo Mayor, habiendo permanecido sus predecesores en el cargo de forma vitalicia. Fue necesaria una Real Orden comunicada a la Real Cámara de Castilla con el nombramiento y la solicitud de que por esa institución se les extienda el título de Alcalde Examinador del Tribunal del Protoalbeitarato. Sin embargo, la destitución se realiza por una simple Orden del Caballerizo Mayor.

86 AGP, Expediente personal de José Victoriano Montero, c. ${ }^{a}$ 699/5. José Victoriano Montero obtuvo el título de Profesor veterinario en la Escuela de Veterinaria de Madrid. Su primer nombramiento en la Real Caballeriza se produce en abril de 1811, viéndose favorecido en sus promociones por su labor como Mariscal Mayor en diferentes Regimientos durante la Guerra de la Independencia (y también de su padre, José M. ${ }^{a}$ Montero, Mariscal de Número de la Real Caballeriza). Ejerce como Mariscal de Número y Alcalde Examinador del Tribunal desde septiembre de 1818.

87 AGP, Expediente personal de José Foraster, c. ${ }^{a}$ 2626/4. José Foraster es Maestro albéitar, su primer nombramiento en la Real Caballeriza data de noviembre de 1807. Cuenta con el favor continuo, incluso promocionando sin respetar el escalafón, del Marqués de Bélgida, Caballerizo Mayor. Ejerce como tercer Alcalde Examinador desde febrero de 1827 al ser habilitado como Mariscal de Número honorario, siendo nombrado como titular de la plaza en abril de 1831. 
5.3. Nuevo nombramiento de los Catedráticos de la Escuela de Veterinaria como Mariscales de Número de la Real Caballeriza y Alcaldes Examinadores del Tribunal del Protoalbeitarato

La absorción estaba realizada de facto, pero surgieron complicaciones. Una serie de trabas de carácter administrativo y de jerarquía de poderes y competencias, propias del entramado político-administrativo del momento, produjo esta última complicación. Estas trabas, como describimos a continuación, derivan tanto de la tajante forma elegida por el Marqués de Cerralbo para realizar la unión entre ambas instituciones como de la arrogancia mostrada por los Catedráticos durante la tramitación de la misma.

El desconocimiento por el Ministerio del Interior tanto de la existencia de la contrata como del nombramiento de nuevos Alcaldes Examinadores, origina la anulación de esto último, dando al traste con el proceso. El Ministro del Interior mediante Real Orden dispone que los dos antiguos Mariscales continúen ejerciendo como Alcaldes Examinadores y que el Protector retire los títulos de nombramiento como Alcaldes Examinadores a los Catedráticos y los remita a su Ministerio. Asimismo, comunica al Secretario del Despacho de Gracia y Justicia que cese todo procedimiento del Juzgado Real ordinario y que la Comisión encargada de formar las Ordenanzas de unión entre Escuela y Tribunal remita su proyecto en breve término ${ }^{88}$.

De forma inmediata, los Catedráticos dirigen sendas instancias a la Reina Gobernadora y al Secretario de Estado y Ministro del Interior, explicando sus razones para mantener la validez de los nombramientos como Alcaldes Examinadores ${ }^{89}$. Vuelven los Catedráticos a reincidir en el mismo error. Crearon el problema al obtener sus nombramientos como miembros del Tribunal del Protoalbeitarato sin seguir el conducto reglamentario, obviando al Ministerio

88 AGUCM, Correspondencia del Ministerio de Fomento, año 1835, c. ${ }^{a}$ V/02-010. Oficio del Protector de la Escuela de Veterinaria dirigido al primer Catedrático, informando del recibido de Real Orden del Ministro del Interior, en Madrid a 20-03-1835.

89 Según explican al Duque de Alagón, la Reina ordena que el Caballerizo Mayor realice nuevamente los nombramientos como Mariscales de Número a favor de los Catedráticos, hecho que se produce a 27 de marzo, por lo que éstos estiman que ya no es necesario que cumplan la Real Orden que les obliga a devolver sus nombramientos como Alcaldes Examinadores; AGUCM, Correspondencia del Ministerio de Fomento, año 1835, c. ${ }^{a}$ V/02-010. Oficio de la Junta de Catedráticos de la Escuela de Veterinaria dirigida al Protector de la Escuela, en Madrid a 30-03-1835. Este segundo nombramiento, realizado a 27 de marzo de 1835, es la explicación a la fecha referida por Casas y Sampedro en su Boletín de Veterinaria, que será recogida posteriormente por Sanz Egaña. 
del Interior, con la correspondiente consecuencia, y vuelven a reincidir al dirigirse a la Reina y al Ministro sin el conocimiento de su superior inmediato, el Protector de la Escuela.

El Duque de Alagón conmina a los Catedráticos a que le devuelvan sus títulos en las siguientes veinticuatro horas, independientemente de que entienda que tras realizarse su nuevo nombramiento como Mariscales de Número, el de Alcaldes Examinadores será consiguiente como prerrogativa aneja ${ }^{90}$. Los Catedráticos ningunean nuevamente al Protector, devuelven los nombramientos directamente al Ministerio del Interior, aunque parecen apuntar cierto arrepentimiento: «... los cuales han sido remitidos, quedandonos el resentimiento de no haverlos podido mandar por conducto de V.E.» ${ }^{91}$.

El 4 de abril de 1835, el Ministro del Interior remite al Protector de la Escuela dos Reales Ordenes: una comunica el archivo y anulación de los títulos de nombramiento enviados por los Catedráticos; y otra, pone en su conocimiento, que tras recibir del Caballerizo Mayor el nuevo nombramiento de los cinco Catedráticos de la Escuela de Veterinaria como Mariscales de Número de la Real Caballeriza realizado por la Reina Gobernadora, cesan en sus obligaciones los anteriores Mariscales, Montero y Foraster. Este nombramiento, al igual que el inicial, se produce a partir de la aprobación de la contrata. La Reina Gobernadora nombra a Carlos Risueño, Nicolás Casas, Guillermo Sampedro, Antonio Santos y José María de Estarrona como Alcaldes Examinadores del Tribunal del Protoalbeitarato, ordenando, a través del Ministerio del Interior, al Secretario del Consejo Real de España e Indias, que por la Sección de Gracia y Justicia se les expidan los títulos correspondientes ${ }^{92}$. Por segunda vez consecutiva se cierra el círculo, la contrata firmada por el Caballerizo Mayor, por la que los cinco Catedráticos se comprometen a ejercer en la Real Caballeriza como Mariscales de Número, es aprobada por la Reina Gobernadora, sucediéndole en el tiempo el Real nombramiento como Alcaldes Examinadores del Real Tribunal del Protoalbeitarato.

90 AGUCM, Correspondencia del Ministerio de Fomento, año 1835, c. ${ }^{a}$ V/02-010. Oficio del Protector de la Escuela dirigido al primer Catedrático, para que lo ponga en conocimiento de la Junta, en Madrid a 1-04-1835.

91 AGUCM, Correspondencia del Ministerio de Fomento, año 1835, c. ${ }^{a}$ V/02-010. Acta de la Junta de Catedráticos de 2 de abril de 1835.

92 AGUCM, Correspondencia del Ministerio de Fomento, año 1835, c. ${ }^{a}$ V/02-010. Oficios del Duque de Alagón comunicados al primer Catedrático, para que ponga en conocimiento de la Junta las Reales Órdenes recibidas, en Madrid a 9-04-1835. En el Acta correspondiente al 13 de abril, los Catedráticos dan cuenta de haber tomado ya posesión de sus destinos. 


\subsection{Creación de la Facultad de Veterinaria}

La Facultad de Veterinaria se crea por Real Decreto de 6 de agosto de 1835, por unión de la Escuela de Veterinaria y el Tribunal del Protoalbeitarato $^{93}$. Lo que oficialmente se presenta como la unión de las dos instituciones, en la práctica, es la absorción del Tribunal por parte de la Escuela. El Real Tribunal del Protoalbeitarato camina hacia su desaparición.

Previa reclamación del Duque de Alagón al Marqués de Cerralbo, realizada en base al Artículo 3. ${ }^{\circ}$ del Real Decreto de creación de la Facultad, se dicta la Real Orden de 8 de septiembre de 1835 , que determina que se ponga a disposición de la Escuela cuanto pertenezca al Tribunal (fondos, archivos, muebles y demás efectos) y no haya sido comprado con fondos de la Real Casa ${ }^{94}$. El Artículo 6. ${ }^{\circ}$ del mismo Real Decreto recoge el manifestado deseo del Duque de Alagón de elevar los derechos de examen de los aspirantes a los títulos de Albéitar y de Herrador, en contra de la propuesta inicial de la Comisión de rebajarlos ${ }^{95}$. Según sus cálculos, esta cantidad ascendería a 183.764 reales durante ese año y sería aplicada al mantenimiento de la Escuela. El Real Decreto determina que los derechos de examen y la expedición de títulos se ingresarán íntegros en la Tesorería de la Escuela, siendo de 1.100 reales el de albéitar, 800 reales el de herrador y 500 reales el de castrador. La Albeitería seguirá siendo una competencia desleal, pero al ser estos ingresos computados a favor de la Escuela, al menos son utilizados en la formación de los nuevos veterinarios. Es general la opinión entre los historiadores veterinarios que la albeitería sufragó los costes de la veterinaria en una época de penuria económica. Esta medida fue una solución a medio plazo, pero sentó las bases de

93 AGUCM, Correspondencia del Ministerio de Fomento, c. ${ }^{a}$ V/01-016. El Real Decreto es comunicado al Protector de la Escuela de Veterinaria por el Secretario de Estado y Ministro del Interior a 8 de agosto de 1835. Este mismo Real Decreto se comunica también a Carlos Risueño, primer Catedrático de la Escuela de Veterinaria, en su calidad de Decano del Tribunal del Protoalbeitarato. AGP, Reinado Isabel II, Caballerizas, c. ${ }^{\text {a }} 4 / 25$. Oficio comunicado por Secretaría de Reales Caballerizas a Mayordomía Mayor, firmado por el Marqués de Cerralbo: «segun comunicacion que se me hace por el Secretario del Despacho de lo Interior, V.M. por Real Decreto de seis del presente, tuvo a bien determinar quedasen unidos la Real Escuela de Veterinaria y el Real Tribunal del Protoalbeitarato, denominandose en lo sucesivo Facultad de Veterinaria», en San Ildefonso a 27-08-1835.

94 AGP, Reinado Isabel II, Caballerizas, c. ${ }^{a} 4 / 25$. El Caballerizo Mayor, en oficio de 2708-1835 dirigido a Mayordomía Mayor, solicita permiso para realizar la entrega de efectos.

95 Duque de Alagón (1835), p. 10. Se opone con diversos argumentos a la propuesta inicial de la Comisión de rebajar el importe exigido por los derechos de examen de los albéitares. 
una prolongada agonía, ya que hasta el Decreto de 1847 no se suprime definitivamente el Real Tribunal y los exámenes de gracia perdurarían algunos años más (1852-55). La dualidad de títulos pervivió con sus poseedores, creando una división en la veterinaria que tardaría generaciones en subsanarse ${ }^{96}$. Por otro lado, para algunos autores la mejora económica que supuso la absorción conllevó una merma en el estado moral de los alumnos de la Escuela, que preferían la obtención de títulos en breve plazo dejando aparte los conocimientos de la Veterinaria ${ }^{97}$.

5.5. Negativa del Marqués de Cerralbo al intento de renovación de la contrata efectuado por los Catedráticos de la Escuela de Veterinaria

Una vez más el Marqués de Cerralbo refuerza la evolución de la veterinaria. Conseguida la absorción en la normativa y en la práctica, se corría el peligro, como en la situación inicial, de que los intereses personales se opusieran al futuro para la profesión: faltaba romper el vínculo con la Real Caballeriza para lograr una veterinaria autónoma.

La permanencia como Mariscales de Número debió resultarles rentable económicamente a los Catedráticos, ya que en enero de 1836, próxima la conclusión de la contrata inicialmente suscrita, presentaron nuevas condiciones con la intención de prorrogarla. El motivo de fondo de los argumentos esgrimidos por los Catedráticos es el económico: quieren seguir percibiendo el dinero que les reporta la asistencia clínica al ganado de la Real Caballeri$\mathrm{za}^{98}$. Se encontraron con la firme oposición del Caballerizo Mayor a la reno-

96 Como se afirma en el libro conmemorativo del bicentenario de la Escuela de Veterinaria de Madrid: «creando problemas de competencias que tuvieron que ser legisladas cuidadosamente con disposiciones como la del 31 de mayo de 1856, y la del 3 de junio de 1857, regulando las atribuciones correspondientes a los dos colectivos»; SUÁREZ (1994), p. 64.

97 Gimenez Gacto, J. (1935), Bosquejo Histórico de la Veterinaria. Discurso de ingreso en la Academia de Medicina del Distrito de Zaragoza, leído el 20 de octubre de 1935, Zaragoza, Cesaraugusta, p. 15.

98 Los hechos expuestos en nuestro trabajo contravienen claramente la versión de Llorente Lázaro, que afirma que los Catedráticos no renovaron la contrata por voluntad propia, ante la dificultad que suponía compatibilizar Cátedra y desplazamientos, debido al servicio en la Real Caballeriza, «mientras la corte estaba en Madrid el servicio de las caballerizas se hacia sin dificultad: pero las habia muy grandes en las llamadas jornadas, al Escorial, Granja, Pardo y Aranjuez, por lo que los catedráticos hubieron de abandonar estos puestos, y en su lugar se colocaron dos ilustres veterinarios militares»; véase: LLORENTE (1856), p. 15. 
vación, por parecerle, entre otros motivos, demasiado elevado el importe de los servicios ofertados, por lo que inicialmente propone que la asistencia clínica y herrado del ganado se realice mediante subasta pública ${ }^{99}$.

El escrito enviado por el Marqués de Cerralbo a la Reina Gobernadora en mayo de 1836 proporciona las claves de los nombramientos como Mariscales de Número de los Catedráticos, y de por qué una vez conseguido su propósito no deben seguir ejerciendo como tales: «cuando en el año proximo pasado los Catedráticos de la Real Escuela Veterinaria convinieron en ser Mariscales de numero de vuestra Real Caballeriza obligandose a asistir, cuidar y herrar el ganado de ella a razón de catorce reales mensuales por cada cabeza, no llevaron otro objeto que el de ser Alcaldes examinadores del Proto-Albeyterato, entonces anexo a aquellas plazas; pero habiendo cesado este pribilegio y de consiguiente sus utilidades, no tuvieron reparo en hacer, finalizado el tiempo de su contrata, nuevas proposiciones» ${ }^{100}$. No cabe duda, la aprobación de la contrata por la que los Catedráticos se comprometen a desempeñar las obligaciones como Mariscales de Número obedece a una única finalidad, que al dejar de ejercer en la Real Caballeriza se mantengan como Alcaldes Examinadores del Real Tribunal del Protoalbeitarato.

A 31 de marzo de 1836 los Catedráticos dejan de prestar servicio en la Real Caballeriza. El puesto es entonces cubierto por Julián Gati, único Herrador de Caminos en activo durante el periodo de permanencia de los Catedráticos como Mariscales de Número. Por Real Orden de 31 de mayo de 1836, con efecto retroactivo desde primero de mayo, se aprueba la nueva Planta, que por iniciativa del Marqués de Cerralbo queda formada únicamente por dos Mariscales de Número ${ }^{101}$. Cuando los Catedráticos de la Escuela de Veterinaria de

99 AGP, Expediente personal de Julián Gati y Miguel, c. ${ }^{a}$ 428/9. Se impone el criterio del Marqués de Cerralbo, y por Real Orden de 5 de marzo de 1836 se desestima la nueva contrata con los Catedráticos por el elevado precio presentado para el herrado y por las dietas que solicitan se les abonen durante las Jornadas a los Reales Sitios formando parte de la Real comitiva, ordenándose realizar subasta pública para la adjudicación del servicio. Los Catedráticos vuelven a insistir, aunque sus argumentos no hacen variar la resolución adoptada.

100 AGP, Expediente personal de Julián Gati y Miguel, c. ${ }^{a}$ 428/9. Informe dirigido a la Reina, en El Pardo a 9-05-1836.

101 Expediente personal de Julián Gati y Miguel, c. ${ }^{a}$ 428/9. Para zanjar definitivamente la polémica con los Catedráticos, el Marqués de Cerralbo solicita a la Reina Gobernadora a 905-1836 la aprobación de una nueva Planta, que implica el nombramiento de dos nuevos Mariscales de Número. Se aprobó su solicitud por Real Orden marginal de 31-05-1836. El Caballerizo Mayor destaca, entre los argumentos aportados, tanto el ahorro económico que supondría el coste anual del servicio como el logro de una mejor asistencia del ganado, tanto 
Madrid cesan como Mariscales de Número de la Real Caballeriza siguen manteniendo su condición de Alcaldes Examinadores del Real Tribunal del Protoalbeitarato, lo que permite el control del Tribunal por la Escuela.

Martín Grande García ${ }^{102}$ y Julián Gati y Miguel ${ }^{103}$ son los Profesores veterinarios nombrados Mariscales de Número de la Real Caballeriza. Cumpliendo las directrices del Marqués de Cerralbo, los nuevos Mariscales de Número tienen únicamente consideración de profesionales sanitarios al servicio de la Real Caballeriza ${ }^{104}$. Por primera vez desde hace más de tres siglos, al ocupar las plazas vacantes los dos nuevos Mariscales de Número de la Real Caballeriza, sus nombramientos no llevarán anexo el de Alcaldes Examinadores del

de día como de noche, al facilitarse la presencia permanente de los Mariscales en la Real Caballeriza, en cuyo edificio se les ha asignado su residencia, frente a la asistencia prestada por los Catedráticos, que vivían fuera de la Casa y debían acudir a sus Cátedras.

102 Martín Grande es Mariscal Mayor del escuadrón de Guardias de la Real Persona en el momento de producirse su nombramiento, siendo destinado al Cuartel de Regalada con un sueldo de 12.000 reales anuales. Era hijo de albéitar. Tuvo una destacada carrera veterinaria: en 1830 recibió del Duque de Alagón un primer premio por su trabajo Memoria sobre el Muermo; ganó por Oposición la Cátedra de Materia Médica, concediéndosele por Real Orden el nombramiento como Catedrático Honorario de la Escuela de Veterinaria; realizó comisiones para la compra de caballos destinados a la Real Caballeriza, desplazándose a Londres, París y Constantinopla. En 1856 escribió Cría caballar. Impugnación al sistema de año y vez, al que seguirá una $2^{a}$ Impugnación, motivadas ambas publicaciones por el sistema de reproducción seguido por Pedro Cubillo, destacado veterinario que ejerce como Mariscal en la Real Yeguada de Aranjuez. Fue nombrado Caballero de la Real y distinguida Orden de Carlos III. Fue miembro fundador de la Real Academia Central de Veterinaria, de la que posteriormente será elegido Vicepresidente. En el Centenario de la Enseñanza de la Zootecnia, celebrado en 1946, se destaca en el n. ${ }^{\circ} 134$ del Boletín de Ciencia Veterinaria, la escuela creada a partir de la obra Zootécnica del Catedrático Agustín Pascual, entre cuyos continuadores sobresalen Pedro Cubillo, Julián Soto «y, sobre todos, Martín Grande».

103 Julián Gati había jurado la Plaza de Herrador de Caminos el 7-02-1832. Al ser nombrado Mariscal de Número fue destinado al Cuartel de Coches con un sueldo de 10.000 reales anuales, igualándose en 1847 al percibido por Martín Grande tras propia solicitud. Gati se mantuvo como Mariscal de Número durante todo el reinado de Isabel II, siendo confirmado tras el derrocamiento de la Reina como Profesor de Veterinaria de la Caballeriza Nacional por la Dirección General del Patrimonio que fue de la Corona. Fue cesado en julio de 1870, aduciéndose como motivo la reducción del número de cabezas de ganado.

104 Se les asigna un sueldo más acorde a su categoría profesional y responsabilidad, sin relación contractual a través de contrata como históricamente había sucedido por considerar a la albeitería como un Oficio de manos. Dejan así de percibir las cantidades estipuladas en la contrata por cada acto profesional realizado y por cada medicamento aplicado, pasando el herrado a ser considerado una más de las obligaciones de su actividad profesional. 
Real Tribunal del Protoalbeitarato, la institución que durante tanto tiempo reguló el acceso a una profesión, la albeitería.

\section{CONCLUSIONES}

El proceso de absorción del Real Tribunal confirma una tendencia secular: la reiterada mirada puesta por la veterinaria, y su precedente la albeitería, en su discurso legitimador, en las iniciativas y evolución de las otras profesiones sanitarias, fijando éstas como modelo a seguir.

La absorción aquí estudiada es un eslabón dentro de una amplia cadena en la que la albeitería gremial fue desplazada por el Real Tribunal del Protoalbeitarato y sus subdelegaciones y éstos a su vez por la veterinaria. Resulta evidente que la transición fue más compleja y larga de lo deseado por la nueva profesión. La historiografía precedente ha destacado como causa de lo anterior los factores económicos y sociales, pero los políticos, señalados por alguno de ellos, no habían sido suficientemente valorados. Como hemos analizado, éstos últimos prevalecieron sobre los restantes, incluidos los técnico-profesionales o sanitarios. Queda dilucidar la verdadera cuota de causalidad entre los factores referidos en la bibliografía.

Por lo descrito, creemos que el discurso histórico desde la veterinaria debe matizarse, y si el análisis de la mayor parte de los historiadores más recientes asigna a la albeitería los valores positivos que en su momento desempeñó, se debe reconocer el juego de intereses en el que la veterinaria también se sumió. Asimismo, la documentación consultada otorga al contexto históricopolítico un gran peso, que sin empañar los méritos de los protagonistas veterinarios, sitúa a éstos en su justo término y nos permite añadir que el Marqués de Cerralbo desarrolló un papel crucial en la absorción del Real Tribunal del Protoalbeitarato por la Real Escuela de Veterinaria.

Fecha de recepción: 12 de febrero de 2008

Fecha de aceptación: 5 de febrero de 2009 